\title{
Monascus spp.: A source of Natural Microbial Color through Fungal Biofermentation
}

\begin{abstract}
The search for naturally produced substitutes for chemical food colorants has led to a resurgence of interest in pigments synthesized by fungi such as Monascus spp. This fungus has been used in Asia for many centuries as a natural color and flavor ingredient in food and beverages. The red pigments are of particular interest, because red is the most popular food color and true natural pigments suitable for applications in food industries are difficult to obtain. As a result of recent efforts to replace synthetic food dyes with natural colorants, pigments produced by Monascus spp. have attracted worldwide attention. Monascus color, categorized as a natural color, has also been widely used as a food supplement and in traditional medicine. The major objective of this review deals with production of natural microbial color by Monascus spp. and addresses the parameters involved in fungal biofermentation. The fungal strains of Monascus spp. can be either fermented in solid state fermentation (SSF) or in submerged fermentation (SmF). SSF and SmF are two commonly used techniques during various fermentation processes. One important aspect in the development of a biofermentation process is the ability and suitability of the Monascus strain to be employed with a suitable medium.
\end{abstract}

Keywords: Monascus spp; Fungi; Biofermentation; Proliferation; Pigments
Review Article

Volume 5 Issue 3 - 2017

\section{Musaalbakri Abdul Manan ${ }^{1 *}$, Rosfarizan Mohamad $^{2}$ and Arbakariya Ariff ${ }^{2}$}

${ }^{1}$ Department of biotechnology and Nanotechnology Research Centre, Malaysian Agricultural Research and Development Institute (MARDI), Malaysia

${ }^{2}$ Department of Bioprocess Technology, Universiti Putra Malaysia (UPM), Malaysia

*Corresponding author: Musaalbakri Abdul Manan, Enzyme and Fermentation Technology Programme, Biotechnology and Nanotechnology Research Centre, Malaysian Agricultural Research and Development Institute (MARDI), Persiaran MARDI - UPM, 43400 Serdang, Selangor, Malaysia, Tel: +603-89536093; Email: bakri@mardi.gov.my

Received: May 17, 2017 | Published: July 14, 2017
Abbreviations: SSF: Solid State Fermentation; SmF: Submerged fermentation

\section{Introduction}

Many synthetic food colorants, particularly red ones, have been banned for use in food products due to their toxicity. This has promoted research into food colorants from natural sources. The less stringent tests necessary for the use of natural colorants and the increase in demand for natural ingredients by the increasingly health conscious have led food manufacturers to relook into the use of natural food colorants [1]. This has also resulted in a proliferation of interest in the development of natural food colorants in recent years. The health concern issues of consumers increase the trend towards replacement of synthetic colorants with natural pigments [2]. It has become clear that no single natural colorant can be used for the whole range of food products, due to sensitivity to physical parameters. It is also true that a traditional food colorant is more likely to obtain approval from regulatory authorities and the acceptance of consumers [3]. The task of food biotechnology is to incorporate modern biotechnology methods to improve the productivity and scale-up in the production of these traditional food colorants.

Color is an important food characteristic. It is also a means for the ultimate acceptance of food. In order to enrich or compensate for the loss of color during processing, food colorants have become important food additives. Color additives are also indispensable in manufacturing industries. Dyes and pigments are used to create new food products and to modify the color of established food products, which show color shifts as a result of manufacture and storage. Dyes and pigments are classified as certified and uncertified food colors [4]. Certified colors are manufactured synthetically to meet strict government specifications. Uncertified colors are usually naturally derived products. Most precursors of chemically based colorants are generally derived from petrochemicals [5]. There is considerable interest worldwide in the development of food colorants from natural sources. One indication of this is the number and distribution of food colorant patents issued in the years 1969 through 1984; the interest in natural colorants is clear, since there were 356 patents on natural sources compared to 71 on synthetics [6]. As synthetic food colorants have been prohibited due to their toxicity, the development of comparatively safe natural food colors is now attracting the great interest of researchers. One alternative method for food colorant production is through microbial fermentation.

Colorants from microbial species offer considerable advantages since they can be produced in any quantity and are not subject to the vagaries of nature [7]. The best known microbial colorants are those produced by the Monascus group, especially M. purpureus, which is traditionally grown on rice in the Orient. Monascus species produce a red color, which may be incorporated into foods. Production of natural pigments from animals, plants and microorganisms is gaining more importance in recent years [8]. These include anthocyanins, betacyanins, cochineal and carmine (extract of the female cochineal insect Dactylopius coccus), lycopene, carotenoids, annatto and saffron, turmeric, riboflavin, grapes, beets, paprika (extract of plant), etc [9]. Microorganisms could be a promising source for natural 
food colorants but, except for the fungus Monascus in the Orient, few attempts have been made to use them. The presence of carotenoids, anthroquinone pigments and chlorophylls has been demonstrated in bacteria, yeasts, fungi and algae [10]. Due to their sensitivity to environmental parameters, no single natural colorant can be used for the whole range of food products, e.g. Safflower Yellow is sensitive to heat treatment while $ß$-carotene from carrot is sensitive to light; Berry color appears red at $\mathrm{pH} 3$ but turns to purple at $\mathrm{pH} 4$ to 6 , and eventually becomes blue at $\mathrm{pH}$ 8. The food industry would need many more natural colorants than the available synthetic colors in order to color different food products $[8,11]$.

It is also true that traditional food colorants are more likely to obtain approval from regulatory authorities and the acceptance of consumers. Thus, the main task of the food biotechnologist is to apply modern biotechnological methods to improving the productivity and application of these traditional food colorants. Many microorganisms contain pigments and may serve as sources of food colors. Monascus sp., a fungus that produces red pigments, shows promise for application in food systems. Monascus pigments have been used to color food for centuries and the traditional method of pigment production involves the growth of the fungus on a solid medium such as steamed rice. This method does not permit easy control of environmental parameters and requires intensive space. There have been reports that Monascus can be cultured in submerged culture systems. The submerged fermentation approach could overcome the drawbacks of the former process. Monascus is usually produced according to empirically found rules and, so far, this fermentation has never been described completely using scientific parameters [12].
Despite this, little work has been performed on synthetic media to produce pigments, especially in submerged fermentation $[13,14]$.

\section{The Microorganism}

Monascus belongs to the phylum Eumycota, subphylum Ascomycotina, class Ascomycetes, order Eurotiales and the family Monascaceae. The genus Monascus includes nine species: M. pilosus, M. purpureus, M. ruber, M. floridanus, M. argentinensis, M. eremophilus, M. lunisporas, M. pallens and M. sanguineus [1518]. This fungus is a source of various secondary metabolites of polyketide structure $[19,20]$ and famous for their fermented products [17].

M. purpureus is a strain of M. ruber van Tieghem, a destructive mold that grows on starch and silage and naturally exists in dairy products [21]. The yeast causes fermentation of cellobiose, maltose, fructose and glucose to occur, but does not ferment cane sugar [22]. Monascus sp. is distinguished as a fungus by its ascospores [23]. These are usually spherical, being $5 \mu \mathrm{m}$ in diameter, or ovoid $(6 \times 5 \mu \mathrm{m})$. In the early stages, the young part of the mycelium is white. However, it rapidly changes to a rich orange and later to a distinctly rich red color, reflecting the increasing acidity of the medium and the production of red-orange hyphae. A deep crimson color is found in the substratum as the culture ages [24]. Figure 1 shows some Monascus spp. available in culture collection at laboratory in Malaysian Agricultural Research and Development Institute (MARDI). The colony of Monascus spp. was thin and spreading with reddish in color, indicating that a substantial amount of red pigment had been produced during growth.

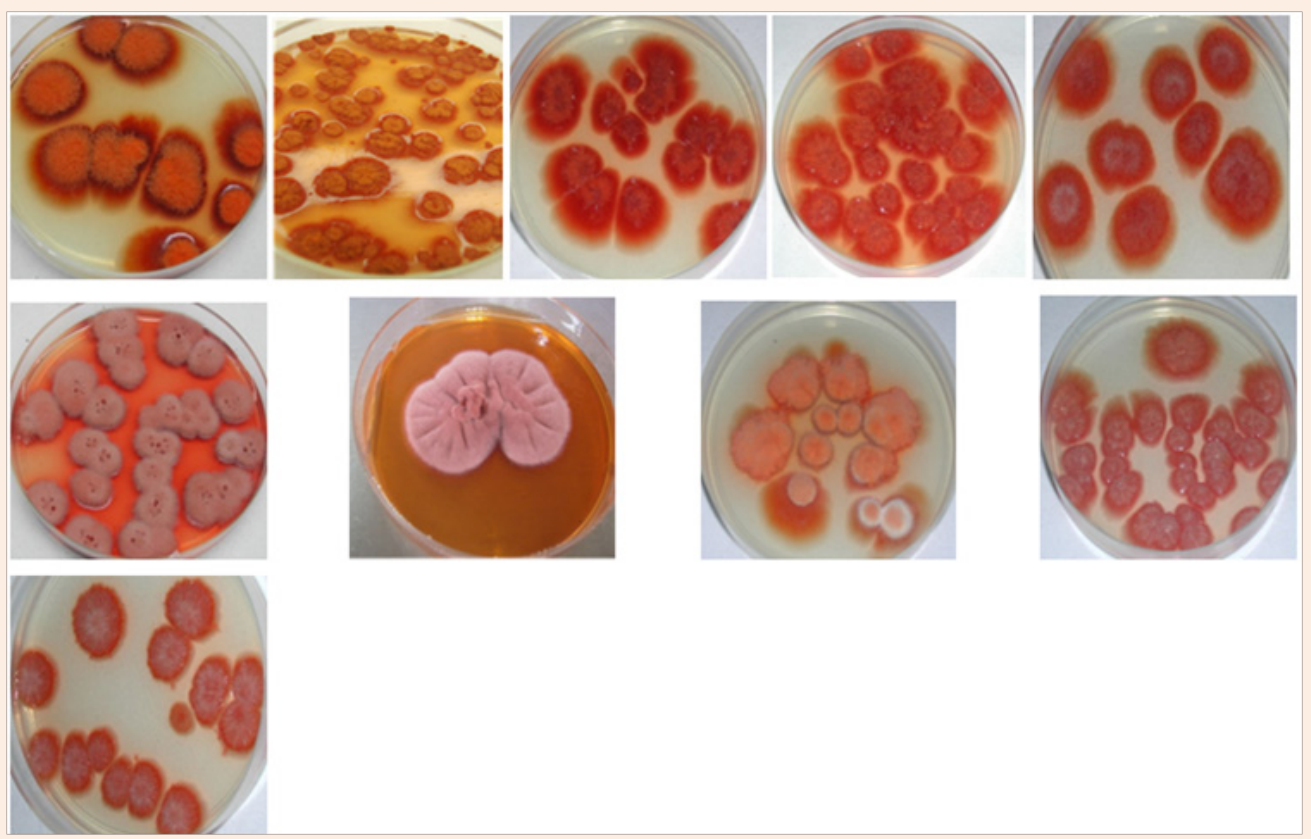

Figure 1: Several species of Monascus spp. from culture collection at laboratory in MARDI. 


\section{Pigments}

It has been reported that Monascus $s p$. produces a mixture of six major pigments of polyketide origin [21] (Figure 2). In recent years, two novel yellow pigments have been recovered [25]. The orange pigments, monascorubrin (M.W.: 382.46) and rubropunctatin (M.W.: 354.40), are synthesized in the cytosol from acetyl coenzyme A by the multienzyme complex of polyketide synthase I $[19,20]$. These compounds possess a unique structure responsible for their high affinity to compounds with primary amino groups (so called aminophiles). Reactions with amino acids yield the major compounds which are watersoluble red pigments, monascorubramine (M.W.: 367.44) and rubropunctamine (M.W.: 339.39) [22,26]. The mechanism of formation of the yellow pigments, ankaflavin (M.W.: 386.49) and monascin (M.W.: 358.43), has not yet been elucidated [20]. These compounds were suggested to originate from chemical oxidation of monascorubrin and rubropunctatin [27,28]. However, their structures strongly suggest that the yellow pigments are reduced derivatives of the orange ones. Thus, the suggestion by Yongsmith et al. [25] that ankaflavin and monascin have their own biosynthetic pathway seems to be more probable.

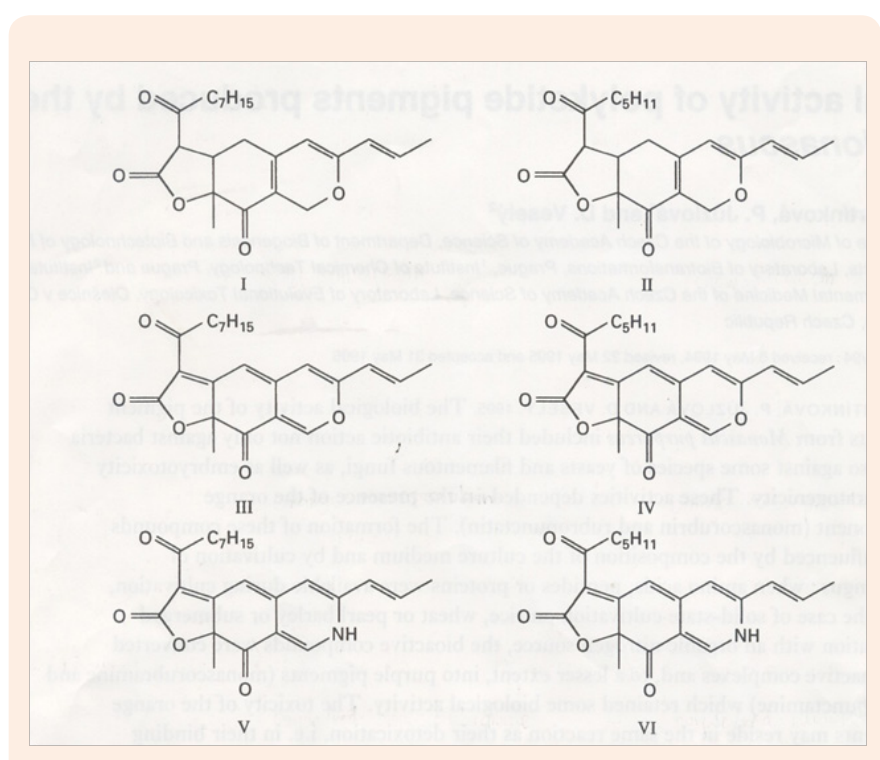

Figure 2: Structures of the yellow [ankaflavin (I), monascin (II)], orange [monascorubrin (III), rubropunctatin (IV)] and red [monascorubramine (V), rubropunctamine (VI)] pigments of Monascus (Sources [21]).

\section{Red Fermented Rice}

Red fermented rice is the fermented product of rice on which the red fungus Monascus has been grown. This fungus is also commonly known as red yeast rice, red rice, red leaven, benikoji (Japanese), hung-chu, hong qu, angkak and zhitai (Chinese) [29]. In traditional practice, red fermented rice is produced by combination of two microorganisms, M. purpureus and yeast. $M$. purpureus is capable of breaking down rice starch into simple sugar, while yeast later continues further conversion into alcohol. In practice, the fungus is fermented on rice and the mycelium develops rapidly until the rich crimson pigment has permeated the grains completely, giving the product its characteristic red color [30]. The whole mass is then ground to a powder and used as a coloring material in food, etc.

Today, red fermented rice is still used in traditional Chinese medicine and in powdered forms as a food coloring in Asia and in Chinese communities in North America, most commonly for coloring fish, alcoholic beverages and cheeses [12]. Considerable interest has been shown in using $M$. purpureus as a nitrite/ nitrate substitute for the preservation of meats and as a potential replacement for synthetic dyes [21]. European manufacturers of meat products have recently popularized its use in coloring sausages and salami [12]. It is interesting to note that a century ago in Asia, red fermented rice was used as a "food disinfectant" $[10,14,31,32]$. The nutritional and medicinal properties of red fermented rice are not fully appreciated by the Western world. Monascus pigments have not been approved by the Food and Drug Administration (FDA) of the USA for use as food colors, but they enjoy a Generally Recognized as Safe (GRAS) status in Asia [11]. This might be due to controversy over their safety which has been provoked because a mycotoxin is also produced along with the Monascus secondary metabolites by certain strains and under certain cultivation conditions $[33,34]$. However, spurred by renewed interest in natural remedies, recent biochemical and pharmacological studies have identified red fermented rice as a beneficial dietary supplement for maintaining a healthy balance of cholesterol and related lipids in the body [35]. The genus Monascus produces the most famous secondary metabolites which have been purified and identified, including monacolins that are responsible for reducing cholesterol levels in blood [33,36,37]. $\gamma$-Aminobutyric acid (GABA), dimerumic acid with medical effects and citrinin as an antibacterial agent have also been identified as secondary metabolites [34,36,38-40]. At the same time, purified pigments from $M$. purpureus show high potential for application in antibacterial therapy and also possess anti-oxidant and antibiotic properties [41]. The annual consumption of Monascus pigments in Japan alone amounted to 600 tons and was valued at 1440 million yen according to a survey done in 1992 [11].

\section{Production}

Although the traditional production of red pigment for use as a coloring agent is conducted on solid support (rice), most studies performed in the laboratory have been done using submerged fermentation $(\mathrm{SmF})$, which presents easily controllable conditions. Solid state fermentation (SSF), however, generally gives a higher yield and productivity of pigment than $\mathrm{SmF}$, but usually needs complex media, which are difficult to use for the elucidation of metabolic pathways and other factors during growth. A comparison was made between submerged and solid media of similar composition, the solid media obtained from the submerged medium by addition of a gelling agent, followed by extrusion in rice-sized particles. The solid media thus prepared supported the production of up to three times more pigment than the corresponding submerged media, but fermentation over rice was still superior [42].

\section{Solid State Fermentation}

The traditional manufacture of red fermented rice is known 
only in certain localities in China. However, Lotong et al. [43] have described procedures for preparing red fermented rice at laboratory scale. The traditional manufacture of red fermented rice includes the following steps: rice is washed, soaked in water for about 1 day and drained thoroughly. The moist rice is then transferred to a glass beaker or suitable container to allow plenty of air space above it and autoclaved for $30 \mathrm{~min}$ at $121^{\circ} \mathrm{C}$. Upon cooling, the rice is inoculated with a sterile water suspension of ascospores prepared from a 25-day- old culture of M. purpureus grown on Sabouraud's agar. At the time of inoculation, the rice should appear rather dry. A wet mushy substrate is undesirable. The inoculated rice is thoroughly mixed and then incubated at 25 to $32^{\circ} \mathrm{C}$ for about 3 days. By this time the rice will have taken on a red color and should be stirred and shaken to redistribute the moisture and kernels with respect to depth from the surface of the fermenting mass. It may be necessary to add some sterile water to replenish moisture lost during incubation. Within about 3 weeks, the rice should take on a deep purplish-red color and kernels should not stick together. After drying at $40^{\circ} \mathrm{C}$, the kernels are easily crumbled by slight force and may be reduced to a powder before using in foods or beverages.

The performance of SSF is influenced by several factors such as the strain of the microorganism employed, the variety of rice, substrate moisture content, nitrogen source, trace elements and aeration [43-45]. Corn can be used as a substrate for producing red pigment. However, non-glutinous varieties of rice are most suitable for preparing red rice, since kernels of glutinous varieties tend to stick together and thus reduce the surface to volume ratio of solid material which is critical for pigment production [43].

In the traditional process of red rice fermentation, the inoculated rice is cultured in bamboo or wooden trays. The treatment of rice and methods used to prepare the inoculum differ slightly between factories. In the culturing steps, however, methods for the successful production of red rice are the knowhow of each producing company. One of the most important parameters is the low initial moisture content. If the fermentation starts at low moisture content, the culture dries out to such a level that the fungus grows poorly and pigmentation does not occur before fermentation is complete [46]. To overcome this problem, an appropriate amount of water is occasionally added throughout the fermentation period [43]. One of the conditions for successful fermentation of fungus for pigment production is employing a low initial substrate humidity $(25-30 \% \mathrm{w} / \mathrm{w})$ which prevents the risk of bacterial contamination and rice grains sticking together [42], and keeps the glucoamylase activity of the fungus low in favor of pigment production [47]. The production process consists of maintaining non-agglutinating rice immersed in water for up to $24 \mathrm{~h}$, and then steaming (autoclaving), addition of an inoculum (a portion of previously fermented rice) and addition of inoculum at time intervals to maintain humidity [31,32]. The humidity needed in the rice fermentation varies according to the traditional description, but it is usually recommended that the humidity be enough to permit growth of mycelium through the grain, without disintegrating the grain. The ideal humidity for pigment production on solid substrates is around $56 \%$ at $\mathrm{pH} 6$ [48].

Another important factor is the oxygen supply. Han et al. [49] recommended oxygen and carbon dioxide partial pressures of 0.5 and $0.02 \mathrm{~atm}$, respectively. Red pigment production is more sensitive than growth to oxygen and carbon dioxide concentrations in the atmosphere. In order to achieve sufficient aeration of the mycelium, it is advisable to separate grains from agglomerates formed during sterilization or cultivation. This separation is quite easy when fermentation is carried out in plastic bags or in a fermenter with a moving bed ("swing" fermenter) [43].

With this microorganism, fermentative production of pigments can be obtained in both SSF and SmF [24]. However, SSF leads to higher yields of pigment that are released into the solid substrate (usually rice grains), while in SmF, the pigments are mainly retained intracellularly, causing inhibition of further production [11]. SSF results in a higher pigment yield than fermentation in shake flasks and it was concluded that this phenomenon could be due to minimal inhibition by the product [50]. In SSF, pigments are released into grains while during $\mathrm{SmF}$ pigment accumulates in the mycelium. However, Evans et al. [5] showed that the better pigment yields by SSF are probably not caused by the extractive effect of rice grains because addition of sorbent particles into SmF does not result in an increase of pigment production. These authors suggested that the reason might be rather the attachment of the mycelium to the grains. Johns et al. [48] suggested that the microscopic porous structure of rice favorably influences cultivation because the substitution of this substrate for carrageenan particles containing all nutrients is not successful. Lin et al. [51] compared various kinds of substrates and found that the use of steamed bread led to the best pigment yield. In addition to rice and bread, oat, corn or wheat grains can serve as substrates for the SSF of Monascus species [44,51]. In order to recreate the physiological conditions of SSF, a strain of $M$. purpureus was immobilized in/on different inert carriers such as Ca-alginate, polyurethane sponge, active carbon and pearlite, and cultivated in SmF and repeated-batch processes [52]. Examples of pigment fermentation by Monascus species are summarized in Table 1 [53-64].

Table 1: Production of pigments from different media by solid state fermentation.

\begin{tabular}{|c|c|c|c|}
\hline Microbial source & Medium & Parameters & Reference \\
\hline $\begin{array}{l}\text { M. purpureus KACC } \\
42430\end{array}$ & Corn cob & $\begin{array}{l}60 \% \text { initial moisture content; incubation at } 30^{\circ} \mathrm{C} \text {; incubation period } \\
7 \text { days; fermentation in } 250 \mathrm{~mL} \text { Erlenmeyer flask }\end{array}$ & {$[53]$} \\
\hline Monascus sp. LPB 31 & Rice & $\begin{array}{l}53 \% \text { initial moisture content; incubation at } 32^{\circ} \mathrm{C} \text {; incubation period } \\
16 \text { days; fermentation in columns and drum bioreactor }\end{array}$ & {$[54]$} \\
\hline $\begin{array}{c}\text { M. purpureus ATCC } \\
\text { 16365, BCC } 6131, \text { DMKU } \\
\text { and FTCMU } \\
\text { M. ruber TISTR } 3006\end{array}$ & Polished adlay & $\begin{array}{l}\text { Incubation at } 32-35^{\circ} \mathrm{C} \text {; incubation period } 28 \text { days; fermentation in } \\
\text { autoclavable polypropylene plastic bag }\end{array}$ & {$[55]$} \\
\hline
\end{tabular}




\begin{tabular}{|c|c|c|c|}
\hline M. purpureus LPB 97 & Jackfruit seed (powder) & $\begin{array}{l}50 \% \text { initial moisture content; incubation at } 30^{\circ} \mathrm{C} \text {; incubation period } \\
7 \text { days; fermentation in } 250 \mathrm{~mL} \text { Erlenmeyer flask }\end{array}$ & {$[56]$} \\
\hline M. purpureus M9 & $\begin{array}{l}\text { Rice, corn, whole } \\
\text { sorghum grain, dehulled } \\
\text { sorghum grain, sorghum } \\
\text { bran }\end{array}$ & Incubation at $30^{\circ} \mathrm{C}$; incubation period 14 days; fermentation in jar & [57] \\
\hline M. purpureus KJR2 & Durian seed & $\begin{array}{l}\text { Incubation at } 30^{\circ} \mathrm{C} \text {; incubation period } 14 \text { days; fermentation in } \\
\qquad 300 \mathrm{~mL} \text { Erlenmeyer flask }\end{array}$ & {$[58]$} \\
\hline M. purpureus MTCC 369 & Corn, sugarcane bagasse & $\begin{array}{l}\text { Incubation at } 30^{\circ} \mathrm{C} \text {; incubation period } 7 \text { days; fermentation in } \\
\qquad 250 \mathrm{~mL} \text { Erlenmeyer flask }\end{array}$ & [59] \\
\hline M. ruber MTCC 2326 & Broken rice & $\begin{array}{l}\text { Incubation at room temperature; incubation period } 15 \text { days; } \\
\text { fermentation in } 250 \mathrm{~mL} \text { Erlenmeyer flask }\end{array}$ & {$[60]$} \\
\hline M. ruber ICMP 15220 & Rice & $\begin{array}{l}70 \% \text { initial moisture content; incubation at } 30^{\circ} \mathrm{C} \text {; incubation period } \\
7 \text { days; fermentation in packed bed solid state bioreactor }\end{array}$ & [61] \\
\hline M. purpureus MTCC 369 & $\begin{array}{l}\text { Long grain, non- } \\
\text { glutinous rice }\end{array}$ & $\begin{array}{l}\text { Incubation at } 30^{\circ} \mathrm{C} \text {; incubation period } 14 \text { days; fermentation in } \\
250 \mathrm{~mL} \text { Erlenmeyer flask }\end{array}$ & [62] \\
\hline M purpureus ATCC 16392 & Rice & $\begin{array}{l}55 \% \text { initial moisture content; incubation at } 30^{\circ} \mathrm{C} \text {; incubation period } \\
10 \text { days; fermentation in Raimbault column solid state bioreactor }\end{array}$ & [63] \\
\hline M. purpureus FTCC 5391 & $\begin{array}{l}\text { Broken rice, rice husk, } \\
\text { pineapple waste, } \\
\text { pressed coconut flesh }\end{array}$ & $\begin{array}{l}65 \% \text { initial moisture content; incubation at } 32^{\circ} \mathrm{C} \text {; incubation period } \\
7 \text { days; fermentation in covered } 500 \mathrm{~mL} \text { beaker }\end{array}$ & [64] \\
\hline
\end{tabular}

\section{Submerged Fermentation}

The composition ratios and productivity of pigments can be influenced by the Monascus strain, medium composition and the fermentation conditions in which they are produced. Therefore, many studies have attempted to enhance the production of Monascus pigments through strain improvement, carbon source change and improvement of culture conditions [65].

\section{Effect of carbon source}

Numerous substances of variable molecular sizes have been utilized effectively as substrates in media for growth of Monascus species and pigment production. Carbon sources supplied in the medium are of great importance to fungi since they provide the carbon needed for the biosynthesis of cellular constituents such as carbohydrates, proteins, lipids and nucleic acids, and their oxidation provides energy for the cell [66]. Glucose is reported by most researchers $[13,22,67-71]$ to be a superior substrate for pigment production by Monascus species. Lin et al. [47,71] indicated that the utilization of carbon sources for growth appears to be strain-specific; glucose and its oligo- and polysaccharide are better than other carbon sources both for growth and pigment production. However, Tseng et al. [72] found glucose to be less suitable for this purpose. This may be caused by strain differences or by other differences in medium composition (glucose concentration, type of nitrogen source). Different carbon sources at varying concentrations produce different types of pigments. However, according to Lin et al. [13], glucose is better than other carbon sources both for growth and pigment production. The quantity of pigment produced is commonly affected by different glucose concentrations. When the glucose concentration is too high it will inhibit the formation of secondary metabolites. Furthermore, it can make the growth slightly acidic but not favorable for pigment production. An initial glucose concentration of $40 \mathrm{~g} / \mathrm{L}$ was found to be enough to give maximum growth and pigment production [6]. A high glucose concentration (50g/L) led to growth rates, pigment synthesis and considerable ethanol production, perhaps due to induction of respirofermentative metabolism (Crabtree effect) in the aerobic SmF of M. purpureus by high glucose levels [67]. It is recommended that glucose be maintained below $20 \mathrm{~g} / \mathrm{L}$ in the culture medium.

On the other hand, after comparing 24 carbon substrates, Lin [50] found soluble starch, galactose and maltose to be most suitable for the production of red pigments in SmF. Lin et al. [13] claimed that maltose is the best carbon source for red pigment production among maltose, glucose and fructose, and gave the maximum yield at $5 \%(\mathrm{w} / \mathrm{v})$ concentration. Between potato starch, corn starch, wheat flour, rice powder and glucose, rice powder was found to favor red pigment production in SmF, and $5-7 \%(\mathrm{w} / \mathrm{v})$ rice powder produced the highest pigment $[36,50]$. Nevertheless, the fermentation medium with fructose as carbon source proved to be most suitable for mycelium growth and pigment production, with maltose and glucose being the second most productive [72]. When sucrose and lactose were used as carbon sources, mycelium growth and pigment production were inhibited. This result might be due to the strain being unable to utilize sucrose and lactose for fermentation and producing some alkaline substances in the SmF. According to Lin et al. $[13,47,71]$, M. purpureus utilizes sucrose and lactose for reproduction, but cannot utilize sucrose for fermentation because M. purpureus lacks the transfer enzyme. Some strains of M. ruber can be also 
grown on cellulose but pigment production is negligible [73].

Stimulation of pigment production by ethanol as a carbon source in some Monascus strains could originate from a higher cellular pool of acetyl CoA formed during fermentation on ethanol in comparison with that on sugars $[69,74,75]$. Ethanol at a concentration of $2 \%(\mathrm{v} / \mathrm{v})$ was used as the sole carbon source for pigment production by M. purpureus, and the specific pigment production was higher than that obtained with fermentation on maltose [74]. However, until now, ethanol has never been intensively studied as a sole carbon source for pigment production by $M$. purpureus. It was only mentioned that ethanol supports pigment production at a greater rate than sugars [69]. Maltitol and glycerol were tested as substrates for pigment production; the former was a superior substrate but the latter resulted in poor pigment production [50]. Fatty acids can be transformed by Monascus into methyl ketones, but cannot be utilized as the sole carbon source [76-78]. Different types of carbon source are used depending upon the Monascus species, as shown in Table 2 [7984].

Table 2: Carbon sources for pigment production by various microorganisms.

\begin{tabular}{|c|c|c|c|}
\hline Carbon Source & $\%(w / v)$ & Microorganism & Reference \\
\hline \multirow{7}{*}{ Glucose } & 1 & Monascus sp. KB20M10.2 & {$[79]$} \\
\hline & \multirow{2}{*}{2} & M. ruber ATCC 96218 & {$[80,81]$} \\
\hline & & M. anka (M-9) & [93] \\
\hline & 2.6 & M. ruber van Tieghem & {$[82]$} \\
\hline & \multirow{2}{*}{5} & M. purpureus UQM 192F (FRR 2190) & {$[68]$} \\
\hline & & Monascus sp. B683 & {$[65]$} \\
\hline & 10 & M. purpureus N11S & {$[31]$} \\
\hline \multirow{2}{*}{ Maltose } & 3 & M. purpureus CСM 8152 & {$[75]$} \\
\hline & 5 & Monascus sp. TTWMB6093 & {$[13]$} \\
\hline Sucrose & 1 & M. kaoliang KB9 & {$[25]$} \\
\hline Ethanol & 2 & M. purpureus CCM 8152 & {$[75]$} \\
\hline Rice starch & 5 & Monascus sp. B683-M171 & {$[11]$} \\
\hline Co-product of biodiesel & Pure & M. ruber & [83] \\
\hline Corn steep liquor & $5-10$ & M. ruber & {$[84]$} \\
\hline
\end{tabular}

\section{Effect of nitrogen source}

Most fungal strains are capable of utilizing inorganic or organic nitrogen sources. Inorganic nitrogen may be supplied as ammonia gas, ammonium salts or nitrates while organic nitrogen sources may be supplied as amino acids, protein, peptone, yeast extract or urea [85]. Ammonia is a good nitrogen source and can be used by most fungi. However, attention must be paid to the specific salt to be used due to $\mathrm{pH}$ variations during ammonium absorption that may cause inconvenience to the culture [86]. Most fungi grow well on a mixture of amino acids but the effectiveness of these compounds as the sole nitrogen source varies considerably [85].

Various requirements for nitrogen source, either inorganic or organic, are provided to the medium in pigment production. Inorganic nitrogen does not influence pigment formation but organic nitrogen such as malt extract, yeast extract, peptone and soybean flour or their combination promotes growth as well as pigmentation [86-88]. The combination of three organic nitrogen sources, i.e. malt extract, yeast extract and peptone, was used for yellow pigment production by Monascus species $[70,79,89]$. The effect of the nitrogen source on SmF of glucose-utilizing Monascus species was described in detail by Carels et al. $[28,90]$. The effect of different nitrogen sources on pigment production by a number of Monascus species concluded that when the source of nitrogen is yeast extract or nitrate, red pigments are formed, whereas with ammonium or ammonium nitrate, orange pigments are formed $[28,90]$. Yeast extract stimulates conidiation, represses the sexual cycle and increases biomass production [21]. Due to the formation of copious amounts of conidia, pigment production remains at a relatively low level. It was proposed that the orange pigments enter reactions with amino acids because the $\mathrm{pH}$ (above 5) in cultures assimilating an organic nitrogen source is favorable for this interaction [91]. Sodium nitrate supports sporulation, limited growth and gives intermediate pigment yields; the use of ammonium chloride results in repression of conidiation and the sexual cycle and leads to the best pigment yields [21,91]. In this medium, the dramatic $\mathrm{pH}$ decrease impairs pigment-amine interactions giving origin to red pigments according to Carels et 
al. [92] and they also reported that nitrogen source determines $\mathrm{pH}$ evolution. In addition to ammonium chloride, peptone also yields superior growth and pigment production when compared with sodium nitrate $[27,28,92]$. The study also reported that monascorubramine (red pigment) is the major product in all media in spite of the low $\mathrm{pH}$ of some fungal cultures.

For the formation of red pigments in MOPS-buffered (3-(N-morpholine) propane sulfonic acid) culture, monosodium glutamate (MSG) is the most favorable nitrogen source [13]. In an unbuffered culture of another Monascus strain, ammonium glutamate gave superior pigment yields [75]. Hajjaj et al. [80,9396] reported that a well-defined chemical medium with MSG as the nitrogen source used in SmF of Monascus shows better control of pigment production. This promotes production and excretion of extracellular pigments [10,22] and also leads to the formation of a glutamic acid-pigment complex [26]. Lee et al. [94] observed that increased MSG concentrations increase biomass but concentrations above $1.5 \mathrm{~g} / \mathrm{L}$ of MSG give increased biomass but decreased pigment production. However, Yoshimura et al. [69] observed that utilization of nitrogen sources for pigment production appears to be strain-specific since other strains produce much more pigment with MSG and sodium nitrate. Tseng et al. [72] reported that basal broth medium containing organic nitrogen (yeast extract) at $8 \mathrm{~g} / \mathrm{L}$ with the addition of $0.3 \mathrm{~g} / \mathrm{L}$ sodium nitrite might be over the maximum requirement for growth and pigment formation, thus resulting in a decreased weight of dry mycelia and pigment production. Some examples of nitrogen used during SmF for pigment production are shown in Table 3.

Table 3: Nitrogen sources for pigment production by various microorganisms.

\begin{tabular}{|c|c|c|c|}
\hline Microorganism & Nitrogen Source & $\%(w / v)$ & Reference \\
\hline Monascus sp. B683-M171 & \multirow{4}{*}{ MSG } & 0.3 & {$[11]$} \\
\hline M. ruber van Tieghem & & 0.5 & {$[26,82]$} \\
\hline M. ruber ATCC 96218 & & 0.5 & {$[95,80]$} \\
\hline M. purpureus CBS 10907 & & 0.5 & {$[26]$} \\
\hline \multirow{2}{*}{ Monascus sp. TTWMB 6042} & MSG & 1.26 & {$[22]$} \\
\hline & $\mathrm{NH}_{4} \mathrm{NO}_{3}$ & 0.3 & {$[13]$} \\
\hline M. purpureus N11S & $\mathrm{NH}_{4} \mathrm{NO}_{3}$ & 0.3 & {$[31]$} \\
\hline \multirow{2}{*}{ M. purpureus UQM 192F (FRR 2190) } & $\mathrm{NH}_{4} \mathrm{Cl}$ & 0.2 & \multirow{2}{*}[68]{} \\
\hline & Bacto Peptone & 0.5 & \\
\hline Monascus sp. B683 & $\mathrm{NH}_{4} \mathrm{Cl}$ & 3 & {$[65]$} \\
\hline \multirow{3}{*}{ M. anka (M-9) } & $\mathrm{NaNO}_{3}$ & 0.3 & {$[77]$} \\
\hline & Peptone & 1 & \multirow{2}{*}[96]{} \\
\hline & Yeast extract & 0.5 & \\
\hline \multirow{3}{*}{ M. kaoliang KB9 } & $\mathrm{NaNO}_{3}$ & 0.02 & \multirow{3}{*}[25]{} \\
\hline & Yeast extract & 0.03 & \\
\hline & Casamino acid & 0.03 & \\
\hline \multirow{3}{*}{ Monascus sp. KB20M10.2 } & Peptone & 2 & \multirow{3}{*}[70,89]{} \\
\hline & Yeast extract & 2 & \\
\hline & Malt extract & 2 & \\
\hline
\end{tabular}

\section{Effect of pH}

The $\mathrm{pH}$ change during cultivation of a microorganism in $\mathrm{SmF}$ depends on the nitrogen source $[27,75]$ and, to a lesser extent, on the carbon source $[12,75]$. The optimal initial pH value must also be selected with respect to the carbon and nitrogen sources used
[50]. Studies by Chen et al. [68] revealed that culture $\mathrm{pH}$ clearly affects fungal growth and pigment synthesis. However, the final mycelium dry weight was often similar between $\mathrm{pH} 4.0$ and 6.5 and they observed red pigment production was always higher at $\mathrm{pH}$ 6.5. Without controlling the $\mathrm{pH}$ and with an initial $\mathrm{pH}$ of 6.5 in batch fermentation, the value of $\mathrm{pH}$ dropped during the early 
stages of fermentation and then increased to around 5.8 when carbon sources become exhausted. This phenomenon was almost the same as the shake flask culture in which $\mathrm{pH}$ decreased during the early stage of fermentation but began to increase to around 8.0 towards the end. This trend was positively correlated with pigment production [69]. The changes of $\mathrm{pH}$ of the medium during the fermentation period may be one of the possible explanations for the transformation of orange pigments to red pigments. Red and yellow Monascus pigments produced by fermentation are changed by adjusting the medium composition and $\mathrm{pH}$ of the fermentation broth $[27,28,90,97]$. Red pigments are formed in yeast extract or nitrate medium at $\mathrm{pH} 6.5$ and orange pigments are formed in ammonium or ammonium nitrate medium at $\mathrm{pH}$ 2.5. More red pigments are produced in fermentations with a final culture $\mathrm{pH}$ of above 6. $\mathrm{pH}$ evolves differently depending on the nitrogen source and different $\mathrm{pHs}$ determine the color of the pigment formed [90]. On the other hand, when $\mathrm{pH}$ is kept constant at $\mathrm{pH} 6.0,7.0$ and 8.0 throughout the fermentation, the pigment productivity, measured as optical density, is less than in fermentation without $\mathrm{pH}$ control [70]. Buhler et al. [83] reported that $M$. ruber favors release of red pigment into the medium when the $\mathrm{pH}$ range is maintained between 5.45 and 6.23 .

Regardless of the initial $\mathrm{pH}$, the final $\mathrm{pH}$ of cultures utilizing the same carbon and nitrogen sources is approximately the same $[24,27,75]$. Yoshimura et al. [69] reported that maintenance of $\mathrm{pH}$ at a constant value during the entire cultivation period is not profitable. On the contrary, Lin et al. [13] carried out successful cultivation at a constant $\mathrm{pH}$ by using MOPS buffer. The change of $\mathrm{pH}$ during growth depends on nitrogen sources, in the first place, and also the carbon sources. Regardless of initial $\mathrm{pH}$, the final $\mathrm{pH}$ tends to be the same [21], usually in the range of $\mathrm{pH} 7$ to 8 [25]. Fermentation media for various Monascus sp. are summarized in Table 4 [98-100].

Table 4: Optimum culture $\mathrm{pH}$ for pigment production by various microorganisms.

\begin{tabular}{|c|c|c|}
\hline Microorganism & pH & Reference \\
\hline M. purpureus CCM 8152 & 4.6 & {$[75]$} \\
\hline Monascus sp. B683-M171 & $5.0-5.7$ & {$[65]$} \\
\hline M. purpureus C322 & $5.0-5.6$ & {$[52]$} \\
\hline M. purpureus N11S & 5.5 & {$[10]$} \\
\hline Monascus sp. TTWMB 6093 & 5.5 & {$[22]$} \\
\hline M. purpureus & 5.5 & {$[47,71]$} \\
\hline Monascus sp. NRRL 1993 & 6 & {$[72]$} \\
\hline Monascus sp. TTWMB 6042 & 6.3 & {$[5]$} \\
\hline M. ruber van Tieghem & 6.5 & {$[13]$} \\
\hline Monascus sp. J101 & & {$[26]$} \\
\hline Murpureus UQM 192F (FRR 2190) & 6.5 & {$[82]$} \\
\hline Monascus sp. KB20M10.2 & 6.5 & {$[67]$} \\
\hline
\end{tabular}

\section{Effect of other medium components}

The only trace element reported to support growth and pigment production by Monascus species is zinc [78,101,102]. This effect could be due to the participation of zinc in the uptake and utilization of the carbon source. According to Lin et al. [13], high concentrations of phosphate and magnesium sulfate $\left(\mathrm{MgSO}_{4}\right)$ inhibit pigment production and the growth is a crescent linear function of $\mathrm{MgSO}_{4}$ concentration, in the range from 0.5 to $16 \mathrm{mM}$. The addition of corn oil stimulates pigment production twofold compared to the control, while the addition of $0.4 \%(\mathrm{v} / \mathrm{v})$ Tween 80 neither affects glucose uptake, nor retards the growth rate, but enhances the pigment productivity (six to eight times, reaching 8535 units of absorbancy/g dry matter) [103]. 
The addition of individual amino acids (such as lysine, histidine, arginine, aspartic acid, threonine, serine, glutamic acid, proline, glycine, alanine, valine, methionine, isoleucine, leucine, tyrosine and phenylalanine) influences neither growth nor pigment production [90]. On the other hand, McHan et al. [102] reported that almost all protein amino acids except lysine stimulate growth. Pigment production is also increased by the addition of nonprotein amino acids, especially methanproline and azetidinecarboxylic acid. Leucine, valine, lysine and methionine have strong negative effects on the formation of hydrophilic red pigments, i.e. pigments containing an amino acid side chain. Leucine is one of a few amino acids that have a strong negative effect on pigment formation. In addition, leucine supports poor pigment formation when used as the sole nitrogen source, yet it neither represses pigment synthase(s) nor inhibits its action. The negative effect of leucine is caused by enhanced decay of pigment synthase(s) [45]. Addition of a crystallization inducer, poly(oxyethylene) sorbitan esters of palmitic acid (Tween), to the fermentation medium results in the production of extracellular pigments [104]. Addition of an adsorbent resin (Amberlite XAD7) to the immobilized Monascus culture greatly increases both the maximum pigment yield and the production rate above those of free-cell fermentations [5]. Peters et al. [77] reported that M. purpureus is able to oxidize fatty acids and methyl ketones growing on a synthetic medium.

\section{Effect of inoculum size}

The age of the inoculum, the medium used for its cultivation, and therefore their physiological states are of the utmost importance in many fermentation processes. If the inoculum used for the production of secondary metabolites is not in the correct physiological state, a considerable decrease in production will occur because the early hours of fermentation determine the future direction the culture will take [97]. Sekiguchi et al. [105] observed in detail that with Penicillium urticae the type of inoculum used greatly influences the level of enzymes present at the beginning of the fermentation and hence the final level of secondary metabolites produced. Although different levels of pigment-synthesizing enzymes were not measured in Monascus, it was reported that in order to obtain well-phased cultures in the production medium it was necessary to have an inoculum that was actively growing and that had no nutritional limitations [97]. They found that only vegetative biomass, very few conidia and no secondary metabolites are produced. The age of the inoculum is always critical, maximum efficiency only being achieved within very fine limits of $1-2 \mathrm{~h}$.

Calam [106] demonstrated the importance of inoculum for maximum production of secondary metabolites (penicillin and griseofulvin) by different microorganisms, especially the type of morphology exhibited by fungi. According to Smith et al. [107] different yields are obtained in penicillin and griseofulvin fermentations using different types of inoculum. From their study, it was shown that biochemical factors, such as the levels of enzyme activity and efficiency, are at least as important as morphology in determining yield, being carried forward from the inoculum to the production stage. Calam et al. [108] also investigated the time at which inoculum quality is determined and the events associated with the process. Their results are again in agreement with the observations with Monascus, in that the initial stage of growth is very important in fixing the future metabolic and morphological pattern of the behavior of the culture [97].

\section{Effect of temperature}

Although growth is not affected, pigment production is greatly influenced by temperature. The optimal cultivation temperature for individual Monascus strains varies from $25^{\circ} \mathrm{C}$ to $37^{\circ} \mathrm{C}$ [47]. Palo et al. [109] studied various conditions of fermentation and found that the optimum temperature for pigment formation is $27^{\circ} \mathrm{C}$. Growth occurs at temperatures as low as $20^{\circ} \mathrm{C}$ and as high as $37^{\circ} \mathrm{C}$ but poor pigmentation results are obtained at these extremes. Panagou et al. [23] reported that M. ruber ascospores isolated from thermally processed green olives are capable of surviving heat treatments and subsequently grow under reduced oxygen levels, resulting in food spoilage. For pigment production, a higher temperature might be more appropriate. A summary of optimum temperatures for the production of Monascus pigments is shown in Table 5[110-111].

Table 5: Optimum temperature for pigment fermentation by various microorganisms.

\begin{tabular}{|c|c|c|}
\hline Microorganism & Temperature $\left.\mathbf{~}^{\circ} \mathbf{C}\right)$ & Reference \\
\hline Monascus sp. NRRL 1993 & 28 & {$[5]$} \\
\hline M. ruber van Tieghem & 28 & {$[26]$} \\
\hline Monascus sp. KB20M10.2 & 28 & {$[82]$} \\
\hline M. kaoliang KB9 & 30 & {$[79]$} \\
\hline M. anka (M-9) & $28-32$ & {$[25]$} \\
\hline Monascus sp. TTWMB 6093 & 29 & {$[96]$} \\
\hline M. purpureus CCM 8152 & 30 & {$[22]$} \\
\hline
\end{tabular}




\begin{tabular}{|c|c|c|}
\hline M. bakeri KB10 & 30 & {$[87]$} \\
\hline M. kaoliang KB9 & 30 & {$[80,95]$} \\
\hline M. ruber ATCC 96218 & 30 & {$[67]$} \\
\hline Monascus sp. UQM 192F (FRR 2190) & 30 & {$[48]$} \\
\hline Monascus sp. B683 & 30 & {$[11]$} \\
\hline M. purpureus Went CRC3150 & 30 & {$[110]$} \\
\hline M. purpureus C322 & 30 & {$[52]$} \\
\hline M. purpureus & & {$[72]$} \\
\hline & 30 & {$[81]$} \\
\hline Monascus sp. J101 & $35,99]$ \\
\hline & 35 & {$[111]$} \\
\hline M. purpureus N11S & 30 & {$[100]$} \\
\hline Monascus sp. TTWMB 6042 & & {$[14]$} \\
\hline
\end{tabular}

\section{Effect of agitation and aeration}

Microorganisms normally vary in their oxygen requirement. The largest utilization of oxygen during the growth of aerobic microorganisms is for respiration. Oxygen acts as a terminal electron acceptor for oxidative reactions to provide energy for cellular activities [112]. Productivity of several fermentations is limited by oxygen availability and it is therefore important to consider the factors, which affect the efficiency in supplying microbial cells with oxygen [113].

Agitation provided in the fermentation process affects mycelium formation. Pigment production has been shown to be proportional to mycelial growth. It was reported that the pigment production in a stirred tank fermenter is high at high agitation rates [69]. These researchers observed that in fermentation with an agitation speed of $300 \mathrm{rpm}$ the mycelial growth is in the form of pulp and pigment production is low. At agitation speeds of 600 and $800 \mathrm{rpm}$, mycelial growth is in the form of intermediate pulp and pellets, and pigment production is substantially higher. However, when the agitation speed is increased to $1200 \mathrm{rpm}$, growth of the fungus is mainly in pellet form and pigment production drops to about half that of fermentation at 600 to $800 \mathrm{rpm}$. From the study, it can be concluded that high agitation speed provides high shear rates that cause the mycelium of the fungus to split, which, in turn, reduces pigment production. Krairak et al. [114] reported that at low agitation speed sedimentation of cells is observed; therefore, the agitation speed must be sufficiently high to obtain cell culture in the form of cell suspension. Musaalbakri et al. [115] observed that fermentation in a $2 \mathrm{~L}$ stirred tank bioreactor is successful at a constant agitation speed of $600 \mathrm{rpm}$ and dissolved oxygen tension (DOT) levels higher than $90 \%$, which are the best conditions for pigment production and cell morphology. Another finding from this study is that a high DOT level $(>80 \%)$ during growth phase was found to be one of the main factors in the production of cell mycelia which have high ability in synthesizing red pigment; it seems that the use of air for the oxygen supply, even at a very high flow rate, is not capable of maintaining DOT at high levels. Moreover, an increase in cell concentration during fermentation causes high broth viscosity. Therefore, a higher agitation speed is necessary during fermentation to avoid cell sedimentation, especially of growth in pellet form in the case of high cell concentrations. Another aspect that is interesting to investigate is the effect of agitation speed, during growth phase and production phase, on red pigment production. Krairak et al. [114] suggested an agitation speed of $100 \mathrm{rpm}$ (during the early stages of fermentation with low cell concentration) and an increase to 250 rpm (during maximum cell growth with high cell concentration) during Monascus fermentation for improvement of red pigment fermentation. As mentioned by Mohamed et al. [116], mixing filamentous fungi entails a delicate balance between promoting a high volumetric oxygen transfer coefficient while keeping low hydrodynamic stresses in the culture microenvironment.

Pigment production is greatly influenced by medium composition and oxygen supply $[98,99,117]$. Monascus species require sufficient aeration and therefore $\mathrm{SmF}$ can proceed only in shaken, preferably baffled flasks [75] or in a well-stirred and aerated fermenter such as a fermenter equipped with an airlift system [118]. Researchers have observed that mass transfer of oxygen to the aqueous phase of the fermentation volume is improved significantly through the use of an airlift fermenter. Recently, Yang et al. [119] observed the influence of oxygen on Monascus pigment and citrine production by M. ruber by shifting the oxygen supply at different stages of production, the initial growth phase, mid-stage phase and later stage. The availability of oxygen appears to affect biomass levels less than pigment production; red pigment production in particular needs vey high oxygen levels [120]. This might occur due to shear forces that may destroy the mycelium and can be overcome by using roller bottles [96]. 


\section{Effect of other physical factors}

Pigment formation is independent of visible light. Broder et al. [73] recommended the cultivation of Monascus species in total darkness for improvement of red pigment production. Wong et al. [121] reported that different morphologies, photoresponses and antibacterial activity of $M$. purpureus can be obtained by induction or mutation using fast-neuron and X-ray irradiation. However, the different mutants of M. purpureus obtained by irradiation using light sources of various wavelengths [such as white light, blue $(430 \mathrm{~nm})$, red $(660 \mathrm{~nm})$, infrared $(730 \mathrm{~nm})$ and ultraviolet (245)] do not show a significant effect on conidiation for red pigment production.

\section{Fermentation Media for Pigment Production}

Different medium formulations have been proposed and used for pigment fermentation by Monascus species and examples are summarized in Table 6. The carbon sources used for pigment production range from simple C3 molecules such as glycerol up to a complex carbon source such as starch. Glucose is mainly used in all cultivation media with a concentration ranging from 20 to $200 \mathrm{~g} / \mathrm{L}$. However, at industrial scale, rice starch can be used in cases of bulk production of red pigment through SSF in a non-purified form that is utilized in pigment production, food preservation and other medical purposes. Also, different organic nitrogen and inorganic nitrogen sources are added to the cultivation medium to enhance pigment production. MSG, with a concentration ranging from 0.5 to $15 \mathrm{~g} / \mathrm{L}$, or yeast extract, malt extract, peptone and combinations are the main common organic nitrogens. On the other hand, ammonium nitrate $\left(\mathrm{NH}_{4} \mathrm{NO}_{3}\right)$ is mainly used as the inorganic nitrogen source for pigment production, followed by sodium nitrate $\left(\mathrm{NaNO}_{3}\right)$. The phosphate source is in the form of either potassium dihydrogen phosphate $\left(\mathrm{KH}_{2} \mathrm{PO}_{4}\right)$ or dipotassium hydrogen phosphate $\left(\mathrm{K}_{2} \mathrm{HPO}_{4}\right)$ with a concentration ranging from 0.1 to $6 \mathrm{~g} / \mathrm{L}$. Other trace inorganic salts for supplementation with $\mathrm{Mg}^{++}, \mathrm{Fe}^{++}, \mathrm{Zn}^{++}$and $\mathrm{K}^{++}$cations are also added in smaller amounts.

Table 6: Media for Monascus fermentation and pigment production.

\begin{tabular}{|c|c|c|}
\hline Strain & Medium Composition (g/L) & Reference \\
\hline \multirow{3}{*}{ Monascus sp. J101 } & $\begin{array}{l}\text { Sucrose, 100; casamino acid, 5; yeast extract, } 3 ; \mathrm{NaNO}_{3}, 2 ; \mathrm{KH}_{2} \mathrm{PO}_{4}, 1 ; \\
\mathrm{MgSO}_{4} .7 \mathrm{H}_{2} \mathrm{O}, 0.5 ; \mathrm{KCl}, 0.5 ; \mathrm{FeSO}_{4} .7 \mathrm{H}_{2} \mathrm{O}, 0.01 ; \text { agar, } 20 ; \text { stock cultures }\end{array}$ & {$[98-100]$} \\
\hline & $\begin{array}{l}\text { Glucose, 50; Bacto Peptone, 20; } \mathrm{KH}_{2} \mathrm{PO}_{4}, 8 ; \mathrm{CH}_{3} \mathrm{COOH}, 2 ; \mathrm{NaCl}, 1 ; \\
\qquad \mathrm{MgSO}_{4} .7 \mathrm{H}_{2} \mathrm{O}, 0.5 \text {; seed cultures }\end{array}$ & {$[98,99]$} \\
\hline & $\begin{array}{c}\text { Glucose, 70; MSG, 5; yeast extract, } 3 ; \mathrm{NaNO}_{3}, 2 ; \mathrm{KH}_{2} \mathrm{PO}_{4}, 1 ; \mathrm{MgSO}_{4} .7 \mathrm{H}_{2} \mathrm{O} \\
0.5 ; \mathrm{KCl}, 0.5 ; \mathrm{FeSO}_{4} .7 \mathrm{H}_{2} \mathrm{O}, 0.01 \text {; fermentation medium; } \mathrm{pH} 6.6\end{array}$ & {$[111]$} \\
\hline $\begin{array}{l}\text { M. purpureus CCRC } 31499,32966, \\
31530 \\
\text { M. ruber CCRC } 31535 \\
\text { M. pilosus CCRC } 31527\end{array}$ & $\begin{array}{l}\text { Shrimp and crab shell powder (SCSP)/sucrose/chitin; yeast extract, } 1 \text {; } \\
\text { polypeptone, } 1 ; \mathrm{KH}_{2} \mathrm{PO}_{4}, 1 ; \mathrm{MgSO}_{4} .7 \mathrm{H}_{2} \mathrm{O}, 0.5 ; \mathrm{FeSO}_{4} \cdot 7 \mathrm{H}_{2} \mathrm{O}, 0.1 ; \mathrm{NaNO}_{3}, 3 \\
\qquad \mathrm{KCl}, 0.5 ; \mathrm{pH} 7.0\end{array}$ & {$[35]$} \\
\hline M. purpureus & $\begin{array}{l}\text { i. Glucose, 20; malt extract, 20; peptone, 1.0; agar, } 20 \text {; } \mathrm{dH}_{2} \mathrm{O} \text {; stock cul- } \\
\text { tures } \\
\text { ii. Glucose, 100; yeast extract, 8; basal broth medium; } \mathrm{pH} 5.5\end{array}$ & [72] \\
\hline M. ruber & $\begin{array}{l}\text { Glucose, 20; MSG, 5; } \mathrm{K}_{2} \mathrm{HPO}_{4}, 5 ; \mathrm{KH}_{2} \mathrm{PO}_{4}, 5 ; \mathrm{CaCl}_{2}, 0.1 ; \mathrm{MgSO}_{4} \cdot 7 \mathrm{H}_{2} \mathrm{O}, 0.5 ; \\
\quad \mathrm{FeSO}_{4} \cdot 7 \mathrm{H}_{2} \mathrm{O}, 0.01 ; \mathrm{ZnSO}_{4} \cdot 7 \mathrm{H}_{2} \mathrm{O}, 0.01 ; \mathrm{MnSO}_{4} \cdot \mathrm{H}_{2} \mathrm{O}, 0.03 ; \mathrm{pH} 6.0\end{array}$ & {$[95,80]$} \\
\hline Monascus sp. KB20M102.2 & $\begin{array}{l}\text { i. Cassava starch, 20; malt extract, 3; yeast extract, 3; peptone, 5; agar, } \\
\text { 15; stock cultures } \\
\text { ii. Glucose, } 30 \text {; malt extract, } 20 \text {; yeast extract, 20; peptone, 20; inocu- } \\
\text { lum } \\
\text { iii. Glucose 10; malt extract, 8.8; yeast extract, 8.8; peptone, 8.8; fer- } \\
\text { mentation medium; pH } 6.5\end{array}$ & {$[70,79,89,114]$} \\
\hline M. purpureus FTC 5391 & $\begin{aligned} \text { i. } & \text { Potato dextrose agar; stock cultures } \\
\text { ii. } & \text { Yeast extract, 3; malt extract, 3; peptone, 5; glucose, 20; inoculum } \\
\text { iii. } & \text { Glucose, 50; MSG, 12; } \mathrm{K}_{2} \mathrm{HPO}_{4}, 2.5 ; \mathrm{KH}_{2} \mathrm{PO}_{4}, 2.5 ; \mathrm{MgSO}_{4} .7 \mathrm{H}_{2} \mathrm{O}, 1.0 \text {; } \\
& \mathrm{KCl}, 0.5 ; \mathrm{ZnSO}_{4} .7 \mathrm{H}_{2} \mathrm{O}, 0.01 ; \mathrm{FeSO}_{4} .7 \mathrm{H}_{2} \mathrm{O}, 0.01 ; \mathrm{MnSO}_{4} .7 \mathrm{H}_{2} \mathrm{O}, 0.03\end{aligned}$ & {$[64,115]$} \\
\hline
\end{tabular}




\begin{tabular}{|c|c|c|}
\hline $\begin{array}{c}\text { M. ruber CCRC } 31535 \\
\text { M. purpureus CCRC 31497, 31498, } \\
\text { 31499, 31501, 31504, 31530, 31540, } \\
\text { 31542, 31615, 32966 } \\
\text { Monascus sp. CCRC 32087, 32808, } \\
\text { 32809 } \\
\text { M. anka M-13 } \\
\text { Monascus sp. S2 }\end{array}$ & $\begin{aligned} \text { i. } & \text { Rice powder, 30; peptone, 9; glycerin, 30; glucose, } 110 ; \mathrm{MgSO}_{4} \cdot 7 \mathrm{H}_{2} \mathrm{O} \text {, } \\
& 1 ; \mathrm{KNO}_{3}, 2 \text {; potato dextrose agar; stock culture } \\
\text { ii. } & \text { Dextrose, } 100 \text {; peptone, } 10, \mathrm{KNO}_{3}, 2 ; \mathrm{NH}_{4} \mathrm{H}_{2} \mathrm{PO}_{4}, 2 ; \mathrm{MgSO}_{4} \cdot 7 \mathrm{H}_{2} \mathrm{O}, 0.5 \text {; } \\
& \text { CaCl }, 0.1 ; \mathrm{pH} 6.0 \text {; inoculum } \\
\text { iii. } & \text { Rice powder, 20; glucose, 40; MSG, 10; peptone, 10; } \mathrm{pH} \text { 5.0; fermen- } \\
& \text { tation medium }\end{aligned}$ & [30] \\
\hline M. purpureus & $\begin{array}{l}\text { Rice powder/glucose/maltose/sucrose, 50; MSG/peptone/NH4NO3/ } \\
\text { NH4Cl, 15; potato dextrose agar; stock cultures }\end{array}$ & [110] \\
\hline M. purpureus C322 & 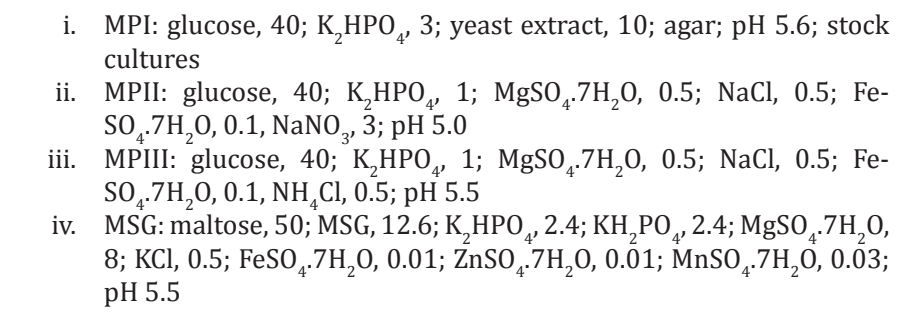 & [52] \\
\hline M. kaoliang KB9 & $\begin{array}{c}\text { Cassava starch, 20; yeast extract, 3; peptone, 5; malt extract, 3; agar; } \\
\text { parent strain; stock cultures }\end{array}$ & {$[25,87,88]$} \\
\hline $\begin{array}{l}\text { M. bakeri KB10 20M10.2 } \\
\text { M. purpureus CBS } 10907\end{array}$ & $\begin{aligned} \text { i. } & \text { Sucrose, } 10 ; \mathrm{KH}_{2} \mathrm{PO}_{4}, 0.1 ; \mathrm{MgSO}_{4} \cdot 7 \mathrm{H}_{2} \mathrm{O}, 0.05 ; \mathrm{NaNO}_{3}, 0.2 ; \mathrm{KCl}, 0.05 \text {; } \\
& \mathrm{FeSO}_{4} \cdot 7 \mathrm{H}_{2} \mathrm{O}, 0.001 \text {; yeast extract, } 0.3 ; \text { casamino acid, } 0.5 ; \text { stock cul- } \\
& \text { tures } \\
\text { ii. } & \text { Cassava starch, } 20 \text {; yeast extract, } 3 \text {; peptone, } 5 \text {; malt extract, } 3 \text {; ino- } \\
& \text { culum } \\
\text { iii. } & \text { Cassava starch, } 30 \text {; soybean flour, } 40 \text {; fermentation medium } \\
\text { i. } & \text { Prickly pear juice } \\
\text { ii. } & \text { Ethanol, 25; MSG, } 4 ; \mathrm{K}_{2} \mathrm{HPO}_{4}, 2.5 ; \mathrm{KH}_{2} \mathrm{PO}_{4}, 5 ; \mathrm{KCl}_{0} 0.5 ; \mathrm{MgSO}_{4} \cdot 7 \mathrm{H}_{2} \mathrm{O} \text {, } \\
& 1 ; \mathrm{FeSO}_{4} \cdot 7 \mathrm{H}_{2} \mathrm{O}, 0.01 ; \mathrm{ZnSO}_{4} \cdot 7 \mathrm{H}_{2} \mathrm{O}, 0.01 ; \mathrm{MnSO}_{4} \cdot \mathrm{H}_{2} \mathrm{O}, 0.03 ; \mathrm{pH} 5.5\end{aligned}$ & [117] \\
\hline Monascus sp. B683-M171 & $\begin{aligned} \text { i. } & \text { Rice, } 50 ; \mathrm{MSG}, 3 ; \mathrm{K}_{2} \mathrm{HPO}_{4}, 2.5 ; \mathrm{KH}_{2} \mathrm{PO}_{4}, 2.5 ; \mathrm{MgSO}_{4} \cdot 7 \mathrm{H}_{2} \mathrm{O}, 1 ; \mathrm{pH} 5-5.7 \\
\text { ii. } & \text { Tapioca starch, 50; } \mathrm{MSG}, 4.5 ; \mathrm{K}_{2} \mathrm{HPO}_{4}, 1.8 ; \mathrm{KH}_{2} \mathrm{PO}_{4}, 1.8 ; \mathrm{MgSO}_{4} .7 \mathrm{H}_{2} \mathrm{O} \text {, } \\
& 0.5 ; \mathrm{pH} 5.5\end{aligned}$ & [11] \\
\hline $\begin{array}{l}\text { M. purpureus CCM } 8152,8152 / 10, \text { ATCC } \\
16362 \\
\text { M. ruber CCM } 8111,8112\end{array}$ & $\begin{array}{l}\text { i. Glucose, 9.13; } \mathrm{NH}_{4} \mathrm{NO}_{3}, 0.045 ; \mathrm{KH}_{2} \mathrm{PO}_{4}, 0.007 ; \mathrm{MgSO}_{4}, 0.006 \text {; malt } \\
\text { extract, } 0.53 \text {; agar; stock cultures } \\
\text { ii. Glucose/fructose/xylose/maltose/starch, 30; ethanol, 20; } \mathrm{NH} 4 \mathrm{Cl} / \\
\text { yeast extract/peptone, } 0.25\end{array}$ & {$[19,20]$} \\
\hline M. ruber & $\begin{array}{l}\text { i. Glucose, 26; MSG, 5; } \mathrm{K}_{2} \mathrm{HPO}_{4}, 5 ; \mathrm{KH}_{2} \mathrm{PO}_{4}, 5 ; \mathrm{MgSO}_{4} \cdot 7 \mathrm{H}_{2} \mathrm{O}, 0.5 ; \mathrm{CaCl}_{2} \text {, } \\
0.5 ; \mathrm{FeSO}_{4} .7 \mathrm{H}_{2} \mathrm{O}, 0.5 ; \mathrm{ZnSO}_{4} \cdot 7 \mathrm{H}_{2} \mathrm{O}, 0.01 ; \mathrm{MnSO}_{4} \cdot \mathrm{H}_{2} \mathrm{O}, 0.03 ; \mathrm{pH} 6.5\end{array}$ & [82] \\
\hline Monascus sp. TTWMB 6093 & $\begin{aligned} \text { i. } & \text { Glucose, 20; yeast extract, 3; malt extract, 3; peptone, 5; agar, 15; } \\
& \text { stock culture } \\
\text { ii. } & \text { Glucose, 20; yeast extract, 3; malt extract, 3; peptone, 5; inoculum } \\
\text { iii. } & \text { Maltose, } 50 ; \mathrm{MSG}_{1} 12.6 ; \mathrm{K}_{2} \mathrm{HPO}_{4}, 2.4 ; \mathrm{KH}_{2} \mathrm{PO}_{4}, 2.4 ; \mathrm{MgSO}_{4} \cdot 7 \mathrm{H}_{2} \mathrm{O}, 0.5 \text {; } \\
& \mathrm{KCl}, 0.5 ; \mathrm{FeSO}_{4} \cdot 7 \mathrm{H}_{2} \mathrm{O}, 0.01 ; \mathrm{ZnSO}_{4} \cdot 7 \mathrm{H}_{2} \mathrm{O}, 0.01 ; \mathrm{MnSO}_{4} \cdot \mathrm{H}_{2} \mathrm{O}, 0.03 ; \mathrm{pH} \\
& 5.5\end{aligned}$ & {$[13,22,47,71]$} \\
\hline M. purpureus CCM 8152 & Ethanol, $20 ; \mathrm{NH}_{4} \mathrm{Cl}, 0.95 ; \mathrm{KH}_{2} \mathrm{PO}_{4}, 2.4 ; \mathrm{MgSO}_{4} .7 \mathrm{H}_{2} \mathrm{O}, 0.5 ; \mathrm{pH} 4.6$ & [75] \\
\hline
\end{tabular}




\begin{tabular}{|c|c|c|}
\hline M. purpureus UQM 192F (FRR 2190) & $\begin{array}{l}\text { i. Potato dextrose agar; stock cultures } \\
\text { ii. Glucose/maltose, 50; NaNO3, 3/NH4Cl, 2/Bacto Peptone, 5; KH- } \\
\text { 2PO4, 1; MgSO4.7H2O, 0.5; trace metals }\end{array}$ & {$[67,68]$} \\
\hline $\begin{array}{l}\text { M. purpureus DSM } 1379 \text {, CBS } 109.7 \\
\text { M. ruber ATCC } 96218 \\
\text { M. pilosus } \\
\text { CBS } 286.34\end{array}$ & $\begin{array}{l}\text { Glucose/ethanol, 20; } \mathrm{MSG}, 5 ; \mathrm{KH}_{2} \mathrm{PO}_{4}, 5 ; \mathrm{K}_{2} \mathrm{HPO}_{4}, 5 ; \mathrm{MgSO}_{4} \cdot 7 \mathrm{H}_{2} \mathrm{O}, 0.5 ; \mathrm{CaCl}_{2} \\
\text { 0.1; } \mathrm{FeSO}_{4} \cdot 7 \mathrm{H}_{2} \mathrm{O}, 0.01 ; \mathrm{ZnSO}_{4} \cdot 7 \mathrm{H}_{2} \mathrm{O}, 0.01 ; \mathrm{MnSO}_{4} \cdot \mathrm{H}_{2} \mathrm{O}, 0.03 ; \mathrm{pH} 6.5\end{array}$ & {$[26,397408]$} \\
\hline M. purpureus DSM 1379 & $\begin{array}{c}\text { Glucose, } 40 / 10 / 0.26 ; \mathrm{NaNO}_{3}, 3 ; \mathrm{KH}_{2} \mathrm{PO}_{4}, 1 ; \mathrm{MgSO}_{4}, 0.5 ; \mathrm{ZnSO}_{4} \cdot 7 \mathrm{H}_{2} \mathrm{O} \\
0.0081 ; \mathrm{MnSO}_{4} \cdot \mathrm{H}_{2} \mathrm{O}, 0.03\end{array}$ & [77] \\
\hline M. purpureus N11S & $\begin{array}{l}\text { i. Medium YEA: yeast extract, 8; glucose, 100; agar, 15; stock cultures } \\
\text { ii. Medium YEB: yeast extract, 8; glucose, 100; fermentation medium }\end{array}$ & {$[10,31,32]$} \\
\hline M. purpureus N11S & $\begin{aligned} \text { i. } & \text { Medium YEA: yeast extract, 8; glucose, 100; agar, 15; stock cultures } \\
\text { ii. } & \text { Glucose, 40/80/150/200; } \mathrm{NH}_{4} \mathrm{NO}_{3}, 0.1-50 ; \mathrm{K}_{2} \mathrm{HPO}_{4}, 6 ; \mathrm{KH}_{2} \mathrm{PO}_{4}, 5 \text {; } \\
& \mathrm{MgSO}_{4}, 0.5 ; \mathrm{KCl}, 0.5 ; \mathrm{FeSO}_{4} \cdot 7 \mathrm{H}_{2} \mathrm{O}, 0.01 ; \mathrm{ZnSO}_{4} \cdot 7 \mathrm{H}_{2} \mathrm{O}, 0.01 ; \mathrm{MnSO}_{4} \text {. } \\
& \mathrm{H}_{2} \mathrm{O}, 0.03\end{aligned}$ & {$[14]$} \\
\hline M. purpureus & $\begin{array}{l}\text { i. Malt extract agar; stock cultures } \\
\text { ii. Malt extract liquid; fermentation medium }\end{array}$ & {$[121]$} \\
\hline Monascus sp. (39 strains) & $\begin{array}{ll}\text { i. } & \text { Glucose, } 40 ; \mathrm{KH}_{2} \mathrm{PO}_{4}, 3 \text {; yeast extract, } 1 \text {; agar, } 15 \text {; stock culture } \\
\text { ii. } & \text { Glucose, 40; } \mathrm{KH}_{2} \mathrm{PO}_{4}, 1 ; \mathrm{MgSO}_{2} .7 \mathrm{H}_{2} \mathrm{O}, 0.5 ; \mathrm{NaCl}, 0.5 ; \mathrm{FeSO}_{4} \cdot 7 \mathrm{H}_{2} \mathrm{O} \text {, } \\
\text { 0.1; fermentation medium with different nitrogen sources, } \mathrm{pH} 2.5\end{array}$ & {$[27,92]$} \\
\hline
\end{tabular}

The production of pigment has also been carried out successfully using immobilized cells. Fenice et al. [52] studied extracellular pigment production by immobilized M. purpureus in repeated-batch processes using different immobilizing carriers such as Ca-alginate, polyurethane sponge, active carbon and pearlite and cultivated in an air lift bioreactor. They found that, with Ca-alginate, pigment production was at a maximum while the cell leakage was negligible and the bead mechanical stability was good; with this carrier, extended repeated-batch fermentation (nine batches, 55 days) was carried out and gave clear indications as to the possibility of maintaining high pigment productivity.

\section{Pigment Analysis Methods and Amounts Produced}

The analysis of pigment produced by Monascus is usually done by measuring absorbance of pigment solutions in the range near 400, 470 and $500 \mathrm{~nm}$, for yellow, orange and red pigments, respectively $[22,48]$. The ratio of absorbance at $500 \mathrm{~nm}$ to the absorbance at $400 \mathrm{~nm}$ gives the ratio between red and yellow pigments [10]. Some researchers analyzed total extracellular and intracellular pigments, summing up the absorbance of extracellular pigments (the absorbance of the liquid culture medium, filtered) and intracellular pigments (the absorbance of an alcoholic extract of the mycelium, filtered) [51,75]. When the fermentation has a solid substrate, the method used must be extraction by water or solvent, with posterior absorbance reading. According to Mapari et al. [122], the pigment characteristics of fungal extracts are comparable to water-soluble natural pigments derived from sources currently in use. The amount of solvent used is usually $5 \mathrm{~mL}$ for each gram of fermented material, and the extraction time varies from 1 to $12 \mathrm{~h}$. Since the samples must, in many cases, be diluted in order to enable reading on a spectrophotometer, absorbance values should not be directly compared, but rather extrapolated to specific absorbance, taking into consideration the dilution factor of the sample [103]. Red pigment solubility is highest in an aqueous solution containing $60-70 \%$ ethanol [75]. Other solvents may be used (acetonitrile, dimethyl sulfoxide, isopropanol), but the only common solvent that extracts pigments more efficiently than ethanol is methanol; it is, however, not recommended for food use because it is toxic.

The fact that the yellow, orange and red pigments of Monascus are produced as a mixture probably affects analysis by simple measurement of absorbance. Nonetheless, the vast majority of authors estimate pigment production by this method, with pigment production ranging from hundreds of absorbance units/mL culture media in SmF, for example, $220 \mathrm{OD}_{510} / \mathrm{mL}$ in optimized conditions by Kim et al. [100,123], to thousands of absorbance units/g dry substrate in SSF, for example, 5430 $\mathrm{OD}_{500} / g$ dry matter [22]. The best procedure for pigment analysis is probably liquid chromatography, which allows separation and quantification of individual pigments; using this method, Hajjaj et al. [80] considered one unit $\mathrm{OD}_{480}$ correspondent to $15 \mathrm{mg} / \mathrm{L}$ of red pigment with $\mathrm{M}=498 \mathrm{~g} / \mathrm{mol}$. Naturally, this equivalence should not be applied to crude pigment extracts, which may contain several substances with different absorbances.

\section{Batch culture}

Batch culture is widely used as the method of production 
for many secondary metabolites using an aerated stirred tank fermenter. Although the traditional production of red fermented rice for use as a coloring agent is conducted on a solid support (rice), most studies performed in the laboratory have been done using batch fermentation, which presents easily controllable conditions [124]. When only the coloring fraction is necessary, without substrate residues, for instance for use in beverages, the pigment must be extracted with an organic solvent, then the solvent must be evaporated, for example using a spray drier. In that case, it may be interesting to work with batch fermentation in which, although the pigment is diluted in a high liquid volume, the biomass and other eventual insoluble components of the fermentation broth may be readily separated by filtration, and then the solvent evaporated. According to Lee et al. [44], Monascus pigment production, although traditionally done by SSF, is industrially performed by batch fermentation. This is due to solid substrate difficulties in aeration, humidity, temperature and $\mathrm{pH}$ control, while these parameters are easily controlled in batch fermentation; besides that, a flexible batch fermentation plant may use the same fermenter for several processes, which is industrially interesting [125]. pH control, for example, may permit direction of the fermentation in order to favor red pigment production [126].

The biosynthesis of pigments by fungi is poorly understood. Studies by many researchers have revealed that pigment production in SmF by Monascus sp. is affected by numerous environmental factors, particularly the type and concentration of nitrogen source in the medium $[27,28,68]$. Unfortunately, the results are often difficult to interpret, due to the use of shake flask cultures, in which the $\mathrm{pH}$ changes during cultivation and is dependent on the nitrogen source used [68]. Furthermore, individual pigment concentrations have not been determined. Wong et al. [14] reported that a Monascus species isolated from the koji of Kaoliang liquor had a maximum yield of pigment in a medium containing $50 \mathrm{~g} / \mathrm{L}$ of rice powder and $5 \mathrm{~g} / \mathrm{L}$ of sodium or potassium nitrate. In addition, they also reported that nitrogen sources such as MSG, peptone and yeast extract or casamino acids are also good nutrients for pigmentation. Carels et al. [27] observed the effect of different nitrogen sources on pigment production of a number of Monascus sp., and concluded that when the source of nitrogen is yeast extract or nitrate, red pigment is formed, whereas with ammonium or ammonium nitrate, orange pigment is formed. For better control of pigment production, a well-defined chemical medium with glutamate as nitrogen source was used in SmF of M. purpureus [95]. This medium formulation promoted production and excretion of extracellular pigments [10] and also led to the formation of a glutamic acid-pigment complex [26].

Batch fermentation using media based on gelatinized cassava starch [45,87], soybean flour [87] and sweet potato [127] has been carried out in an attempt to increase the concentration of carbohydrates using these particular substrates, which are cheap and colorless. Using the starch as a block, there are plenty of carbon sources for the microorganism, but it does not increase the medium viscosity with free starch and thus does not compromise oxygen transfer known to be necessary $[11,45,65]$. Improvement of pigment production and optimization of medium composition and some of the culture conditions such as aeration rate, agitation, $\mathrm{pH}$, dissolved oxygen and addition of substrates during batch culture have been studied in the literature [66-68,87-89,119]. Buhler et al. [62] showed the feasibility of the production of pigment by $M$. ruber in a batch bioreactor using a co-product of biodiesel without previous treatment as a substrate. According to Lee et al. [67] the production of both yellow and red pigments appears to be parallel to the growth curve, and both pigment production and growth end at around $140 \mathrm{~h}$ of culture time. The production of pigments in Monascus cultures appears to be growth-associated. Other researchers also observed the growthassociated pigment production kinetics of Monascus $[49,69]$.

\section{Current Trends and Future Perspectives}

The open literature clearly demonstrates the great importance of studying Monascus in controlled, well-phased cultures and, above all, the importance of studying the early developments of the culture, because it is this phase together with the physiological state of the inoculum which determines the later stages of development. Apart from being a potential producer of industrially interesting pigments, Monascus provides a very elegant model of how fungi can use their metabolism to survive in different environments and how quickly they can adapt. Monascus seems to have evolved in a way whereby it can quickly change its metabolism, switching from one glycolytic pathway to another, thereby changing the form from sporulation to secondary metabolism and vice versa in a very short period of time. Monascus pigments are classified as versatile natural microbial colors that have a wide range of applications in food besides their use in nutraceutical/pharmaceutical industries. Monascus produces pigments that contain compounds responsible for inhibiting cholesterol synthesis and can decrease the level of total cholesterol and serum triglycerides [126]. A recent invention showed how Monascus fungus can be used as a bio-agent to treat agricultural by-products through biofermentation and conversion to Monascus fermented products. Monascus fermented products have high potential as an alternative protein-rich or functional feed ingredient in the diet of growing chickens (specific for layers). It will carry some benefits for cholesterol properties, for example targeting low cholesterol eggs due to the bioactive components of functional Monascus fermented products such as monacolin $\mathrm{K}$ and polysaccharides [127]. Therefore, the production of Monascus fermented products by utilizing agro-industrial by-products may not only reduce process costs but also help in environmental management.

The ability of Monascus spp, in producing red pigment may be improved further by the application of genetic engineering techniques or genomics levels due to the increasing demands of the industry for the development of natural pigments $[128,129]$. On top of that, with the current situation, the use of nutraceutical supplements such as Monascus fermented products by the communities is growing tremendously due to health concerns. Many studies reported in open literature review that different Monascus fermented products preparations contain dissimilar amounts of monacolin levels as well as different production of 
bioactive compounds by Monascus spp. In other words, different strains of Monascus cultivated in different growth conditions may produce Monascus fermented products with different types and quantities of pigment, monacolin and monacolin derivatives. Therefore, the methods for improving of products quality and safety as well as proper information of Monascus fermented products that are available for consumers need to be developed.

\section{Concluding Remarks}

In order to design a reasonable and feasible biotechnological process for production of natural microbial color, optimal process control, medium formulation and an accurate experimental design should be investigated. Detailed investigations are required in order to establish the best medium for Monascus biofermentation. Kinetic studies are also important to give a better understanding of the process and also to give an idea regarding the productivity of Monascus culture, through the determination of specific growth rate, specific product formation rate and substrate consumption rate. Information on kinetics is important for the future scaling-up and development of process control for improvement of pigment production.

\section{Acknowledgement}

The author would like to thank anonymous reviewers for their comments and help with improving this manuscript.

\section{Disclosure Statement}

The authors report no conflicts of interest. The author alone is responsible for the content and writing the paper.

\section{References}

1. Dawson TL (2009) Biosynthesis and synthesis of natural colours. Coloration Technology 125(2): 61-73.

2. Malik K, Tokkas J, Goyal S (2012) Microbial pigments: A review. International Journal of Microbial Resource Technology 1: 361-365.

3. Dufosse L (2006) Microbial production of food grade pigments. Food Technol Biotechnol 44(3): 313-321.

4. Arnold LE, Lofthouse N, Hurt E (2012) Artificial food colors and attention-deficit/hyperactivity symptoms: Conclusion to dye for. Neurotherapeutics 9(3): 599-609.

5. Evans PJ, Wang HY (1984) Pigment production from immobilized Monascus spp utilizing polymeric resin adsorption. Applied and Environmental Microbiology 47(6): 1323-1326.

6. Francis FJ (1987) Lesser-known food colourants. Food Technology, pp. 62-68.

7. Tuli HS, Chaudhary P, Beniwal V, Sharma AK (2015) Microbial pigments as natural color sources: current trands and future perspective. J Food Sci Technol 52(8): 4669-4678.

8. Sigurdson G, Tang P, Giusti MM (2017) Natural colorants: Food colorants from natural sources. Ann Rev Food Sci Technol 8: 261280.

9. Wrolstad RE, Culver CA (2012) Alternatives to those artificial FD\&C food colorants. Ann Rev Food Sci Technol 3: 59-77.
10. Wong HC, Koeheler PE (1983) Production of red water-soluble Monascus pigments. Journal of Food Science 48(4): 1200-1203.

11. Lee YK (1995) Natural colors from microbial sources. Proceedings of the National Seminar on Food Technology-Food Ingredients, Kuala Lumpur, Malaysia, pp. 189-197.

12. Juzlova P, Rezanka T, Viden I (1998) Identification of volatile metabolites from rice fermented by the fungus Monascus purpureus (an-kak). Folia Microbiologica. 43(4): 407-410.

13. Lin TF, Demain AL (1991) Effect of nutrition of Monascus spp. on formation of red pigments. Applied Microbiology and Biotechnology 36(1): 70-75.

14. Wong HC, Lin YC, Koehler PE (1981) Regulation of growth and pigmentation of Monascus purpureus by carbon and nitrogen concentrations. Mycologia 73(4): 649-654.

15. Hawksworth DL, Pitt JI (1983) A new taxonomy for Monascus species based on cultural and microscopical characters. Australian Journal of Botany 31(1): 51-61.

16. Barnard EL (1987) A new species of Monascus from pine tissues in Florida. Mycologia 79(3): 479-484.

17. Martinkova L, Juzlova P, Kren V, Kucerova Z, Havlicek P, et al. (1999) Biological activities of oligoketide pigments of Monascus purpureus. Food Addit Contam 16(1): 15-24.

18. Martinkova L, Juzlova P, Vesely D (1995) Biological activity of polyketide pigments produced by the fungus Monascus. Journal of Applied Bacteriology 79(6): 609-616.

19. Juzlova P, Martinkova L, Kren V (1996a) Secondary metabolites of the fungus Monascus: a review. Journal of Industrial Microbiology 16(3): 163-170.

20. Lin TF, Yakushijin K, Buchi GH, Demain AL (1992) Formation of water-soluble Monascus red pigments by biological and semisynthetic processes. Journal of Industrial Microbiology 9(3-4): 173179.

21. Panagou EZ, Katsaboxakis CZ, Nychas GJE (2002) Heat resistance of Monascus ruber ascopores isolated from thermally processed green olives of the conservolea variety. Int J Food Microbiol 76(1-2): 1118.

22. Juzlova P, Rezanka T, Martinkova L, Kren V (1996b) Long-chain fatty acids from Monascus purpureus. Phytochemistry 43: 151-153.

23. Yongsmith B, Krairak S, Bavavoda R (1994) Production of yellow pigments in submerged culture of a mutant of Monascus spp. Journal of Fermentation and Bioengineering 78(3): 223-228.

24. Blanc PJ, Loret MO, Santerre AL, Parailleux A, Prome D, et al. (1994) Pigments of Monascus. Journal of Food Science 59(4): 862-865.

25. Carels M, Shepherd D (1978) The effect of $\mathrm{pH}$ and amino acids on conidiation and pigment production of Monascus major ATCC 16362 and Monascus rubiginous ATCC 16367 in submerged and shaken culture. Can J Microbiol 24(11): 1346-1357.

26. Carels M, Shepherd D (1977) The effect of different nitrogen sources on pigment production and sporulation of Monascus species in submerged, shaken cultures. Can J Microbiol 23(10): 1360-1372.

27. Iizuka H, Lin CF (1980) On the genus Monascus of Asia and its specific characteristics. Advances in Biotechnology 2: 555-561. 
28. Mapari SA, Thrane U, Meyer AS (2010) Review: Fungal polyketide azaphilone pigments as future natural food colorants? Trends in Biotechnol 28(6): 300-307.

29. Wong HC, Koeheler PE (1981a) Mutant for Monascus-pigment production: a research note. Journal of Food Science 46(3): 956957.

30. Wong HC, Koeheler PE (1981b) Production and isolation of an antibiotic from Monascus purpureus and its relationship to pigment production. Journal of Food Science 46(2): 589-592.

31. Syed MB (2015) Production and applications of natural food colorant from the fungal genus-Monascus. International Journal of Advances in Pharmacy Medicine and Bioallied Sciences 2(3): 178188.

32. Lin YL, Wang TH, Lee HM, Su NW (2008) Biologically active components and nutraceuticals in the Monascus-fermented rice: A Review. Appl Microbiol Biotechnol 77(5): 965-973.

33. Wang SL, Yen YH, Tsiao WJ, Chang WT, Wang CH (2002) Production of antimicrobial compounds by Monascus purpureus CCRC31499 using shrimp and crab shell powder as a carbon source. Enzyme and Microbial Technology 31: 337-344.

34. Su YC, Wang JJ, Lin TT, Pan TM (2003) Production of the secondary metabolites $\gamma$-aminobutyric acid and monacolin K by Monascus. J Ind Microbiol Biotechnol 30(1): 41-46.

35. Li C, Jiang Q Li Y (1998) Monascus purpureus-fermented rice (red yeast rice): a natural food product that lowers blood cholesterol in animals models of hypercholesterolemia. Nutrition Research 18: 71-81.

36. de Carvalho JC, Oishi BO, Pandey A, Soccol R (2005) Biopigments from Monascus: Strains selection, citrinin production and colour stability. Braz Arch Biol Technol 48(6): 885-894.

37. Blanc PJ, Laussac JP, Le Bars J, Le Bars P, Loret MO, et al. (1995) Characterization of monascidin A from Monascus as citrinin. Int Food Microbiol 27(2-3): 201-213.

38. Blanc PJ, Loret MO, Goma G (1995) Production of citrinin by various species of Monascus. Biotechnology Letters 17(3): 291-294.

39. Mukherjee G, Singh SK (2011) Purification and characterization of a new red pigment from Monascus purpureus in submerged fermentation. Process Biochemistry 46(1): 188-192.

40. Teng SS, Feldheim W (2001) Anka and anka pigment production. J Ind Microbiol Biotechnol 26(5): 280-282.

41. Lotong N, Suwanarit P (1990) Fermentation of ang-kak in plastic bags and regulation of pigmentation by initial moisture content. Journal of Applied Bacteriology 68(6): 565-570.

42. Hesseltine CW (1965) A millennium of fungi, food and fermentation. Mycologia 57: 149-197.

43. Lee YK, Chen DC, Chauvatcharin S, Seki T, Yoshida T (1995) Production of Monascus pigments by a solid-liquid state culture method. Journal of Fermentation and Bioengineering 79: 516-518.

44. Yongsmith B, Kitprechavanich V, Chitradon L, Chaisrisook C, Budda N (2000) Color mutants of Monascus sp. KB9 and their comparative glucoamylases on rice solid culture. Journal of Molecular Catalysis B: Enzymatic 10(1-3): 263-272.
45. Lin TF, Demain AL (1994) Leucine interference in the production of water-soluble Monascus pigments. Archives of Microbiology 162(12): 114-119.

46. Johns MR, Stuart DM (1991) Production of pigments by Monascus purpureus in solid culture. Journal of Industrial Microbiology 8(1): 3-28.

47. Han O, Mudgett RE (1992) Effects of oxygen and carbon dioxide partial pressures on Monascus growth and pigment production in solid-state fermentation. Biotechnology Progress 8(1): 5-10.

48. Lin CF (1973) Isolation and cultural conditions of Monascus sp for the production of pigment in a submerged culture. Journal of Fermentation Technology 51: 407-414.

49. Lin CF, Iizuka H (1982) Production of extracellular pigment by a mutant of Monascus kaoliang sp. novel. Appl Environ Microbiol 43(3): 671-676.

50. Fenice M, Federici F, Selbmann L, Petruccioli M (2000) Repeatedbatch production of pigments by immobilized Monascus purpureus: short communication. Journal of Biotechnology 80(3): 271-276.

51. Velmurugan P, Hur H, Balachandar V, Kamal-Kannan S, Lee KJ, et al. (2011) Monascus pigment production by solid-state fermentation with corn cob substrate. J Biosci Bioeng 112(6): 590-594.

52. de Carvalho JC, Pandey A, Oishi BO, Brand D, Rodriquez-Leon JA, et al. (2006) Relation between growth, respiratory analysis and biopigments production from Monascus by solid-state fermentation. Biochemical Engineering Journal 29: 262-269.

53. Pattanagul P, Pinthong R, Phianmongkhol A, Tharatha S (2008) Mevinolin, citrinin and pigments of adlay angkak fermented by Monascus sp. Int J Food Microbiol 126(1-2): 20-23.

54. Babitha S, Soccol CR, Pandey A (2007) Solid-state fermentation for the production of Monascus pigments from jackfruit seed. Bioresour Technol 98(8): 1554-1560.

55. Srianta I, Zubaidah E, Estiasih T (2016) Comparison of Monascus purpureus growth, pigment production and composition on different cereal substrates with solid state fermentation. Biocatalysis and Agricultural Biotechnology 7: 181-186.

56. Srianta I, Novita Y, Kusumawati N (2012) Production of Monascus pigments on durian seed: Effect of supplementation of carbon source. Journal of Pure and Applied Microbiology 6(1): 1-5.

57. Rajeswari TR, Ponnusami V, Sugumaran KR (2014) Production of Monascus pigment in low cost fermentation. International Journal of ChemTech Research 6(5): 2929-2932.

58. Vidyalakshmi R, Paranthaman R, Murugesh S, Singaravadivel K (2009) Microbial bioconversion of rice broken to food grade pigments. Global Journal of Biotechnology and Biochemistry 4(2): 84-87.

59. Said FM, Chisti Y, Brooks J (2010) The effects of forced aeration and intial moisture level on red pigment and biomass production by Monascus ruber in packed bed solid state fermentation. International Journal of Environmental Science and Development 1(1): 1-4.

60. Ahmad M, Pandam BP (2014) Optimization of red pigment production by Monascus purpureus MTCC 369 under solid-state fermentation using response surface methodology. Songklanakarin Journal of Science and Technology 36(4): 439-444. 
61. Rosenblitt A, Agosin E, Delgado J, Perez-Corres R (2000) Solid substrate fermentation of Monascus purpureus: Growth, carbon balance and consistency analysis. Biotechnol Prog 16(2): 152-162.

62. Musaalbakri AM, Ariff A, Rosfarizan M, Ismail AKM (2006) Aeration and agitation strategies for the improvement of red pigment production by Monascus purpureus FTC 5391. Journal of Tropical Agriculture and Food Science 34(1): 89-102.

63. Lee YK, Lim BL, Ng AL, Chen DC (1994) Production of polyketide pigments by submerged culture of Monascus: Effects of substrates limitations. Asia Pasific Journal of Molecular Biology and Biotechnology 2(1): 21-26.

64. Gadd GM (1988) Carbon nutrition and metabolism In: Berry DR (Ed.) Physiology of Industrial Fungi. Blackwell Scientific Publications, London, UK, pp. 21-37.

65. Broder CU, Koehler PE (1980) Pigments produced by Monascus purpureus with regard to quality and quantity. Journal of Food Science 45(3): 567-569.

66. Chen MH, Johns MR (1994) Effect of carbon source on ethanol and pigment production by Monascus purpureus. Enzyme Microbiology Technology 16: 584-590.

67. Chen MH, Johns MR (1993) Effect of $\mathrm{pH}$ and nitrogen source on pigment production by Monascus purpureus. Applied Microbiology Biotechnology 40(1): 132-138.

68. Yoshimura M, Yamanaka S, Mitsugi K, Hirose Y (1975) Production of Monascus pigment in a submerged culture. Agricultural Biological Chemistry 39(9): 1789-1795.

69. Krairak S, Yamamura K, Nakajima M, Shimizu H, Chim Anage P, et al. (1999b) Maximum yellow pigment production utilizing a fed-batch culture. Biotechnology for Sustainable Utilization of Biological Resources in the Tropics 14: 210-216.

70. Lin TF, Demain AL (1995) Negative effect of ammonium nitrate as nitrogen source on the production of water-soluble red pigments by Monascus sp. Applied Microbiology and Biotechnology 43(4): 701705.

71. Tseng YY, Chen MT, Lin CF (2000) Growth, pigment production and protease activity of Monascus purpureus as affected by salt, sodium nitrite, polyphosphate and various sugars. J Appl Microbiol 88(1): 31-37.

72. Fabre CE, Santerre AL, Loret MO, Baberian R, Pareilleux A, et al. (1993) Production and Food Applications of the Red Pigments of Monascus ruber. Journal of Food Science 58(5): 1099-1102.

73. Juzlova P, Martinkova L, Lozinski J, Machek F (1994) Ethanol as substrate for pigment production by the fungus Monascus purpureus. Enzyme and Microbial Technology 16: 996-1001.

74. Kranz C, Panitz C, Kunz B (1992) Biotransformation of free fatty acids in mixtures to methyl ketones by Monascus purpureus. Applied Microbiology and Biotechnology 36(4): 436-439.

75. Peters N, Panitz C, Kunz B (1993) The influence of carbohydrate dissimilation on the fatty acid metabolism of Monascus purpureus. Applied Microbiology and Biotechnology 39(4-5): 589-592.

76. Johnson MR, McHan F (1975) Some effects of zinc on the utilization of carbon sources by Monascus purpureus. Mycologia 67(4): 806816.

77. Krairak S, Yamamura K, Irie R, Nakajima M, Shimizu H, et al. (2000) Maximizing yellow pigment production in fed-batch culture of Monascus sp. J Biosci Bioeng 90(4): 363-367.
78. Hajjaj H, Blanc PJ, Groussac E, Goma G, Uribelarrea JL, et al. (1999) Improvement of red pigment/citrinin production ratio as a function of environmental conditions by Monascus ruber. Biotechnol Bioeng 64(4): 497-501.

79. Hajjaj H, Blanc PJ, Groussac E, Uribelarrea JL, Goma G, et al. (2000) Kinetic analysis of red pigment and citrinin production by Monascus ruber as a function of organic acid accumulation. Enzyme Microb Technol 27(8): 619-625.

80. Mak NK, Fong WF, Leung, WYL (1990) Improved fermentative production of Monascus pigments in roller bottle cultures. Enzyme and Microbial Technology 12: 965-968.

81. Pastrana L, Blanc PJ, Santerre AL, Loret MO, Goma G (1995) Production of red pigments by Monascus ruber in synthetic media with a strictly controlled nitrogen source. Process Biochemistry 30(4): 333-341.

82. Buhler RMM, Dutra AC, Vendruscolo F, Moritz DE, Ninow JL (2013) Monascus pigment production in bioreactor using a co-product of biodiesel as substrate. Cienc Tecnol Aliment 33(1): 9-13.

83. Hamano PS, Kilikian BV (2006) Production of red pigments by Monascus ruber in culture media containing corn steep liquor. Braz J Chem Eng 23(4): 443-449.

84. Slaughter JC (1988) Nitrogen metabolism. In: Berry DR (Eds.), Physiology of Industrial Fungi. Blackwell Scientific Publications, London, UK, p. 58-60.

85. Ariff AB (1993) The influence of mode of operation on the production of glucoamylase by Aspergillus awamori. University of Manchester, Manchester, UK.

86. Yongsmith B, Krairak S, Chaisrisook C, Chimanage P, Tanaka A, et al. (1997) Fermentation of yellow pigments by cassava starch utilizing Monascus spp. Biotechnol Sustain Util Biol Resour Trop 12: 235244.

87. Yongsmith B, Chaisrisook C, Chimanage P, Budda N, Krairak S, et al. (1998) Nature of nitrogen sources on yellow pigmentation of Monascus sp. KB 20M10.2. Biotechnol Sustain Util Biol Resour Trop, pp. 841-847.

88. Krairak S, Yamamura K, Nakajima M, Shimizu H, Chim-Anage P, et al. (1997) The yellow pigment production from cassava starch by Monascus sp. Biotechnol Sustain Util Biol Resour Trop 12: 230-234.

89. Shepherd D (1977) The relationship between pigment production and sporulation in Monascus. In: Meyrath J \& Bu'lock JD (Eds.), Biotechnology and Fungal Differentiation. FEMS Symposium 4, Academic Press, London, UK, pp. 103-118.

90. Mostafa ME, Abbady MS (2014) Secondary metabolites and bioactivity of the Monascus pigments review article. Global J Biotech \& Biochem 9(1): 1-13.

91. Carels M, Shepherd D (1979) The effect of changes in pH on phosphate and potassium uptake by Monascus rubiginosus ATCC 16367 in submerged shaken culture. Can J Microbiol 25(12): 14841488.

92. Hajjaj H, Klaebe A, Goma G, Blanc PJ, Barbier E, et al. (2000) Mediumchain fatty acids affect citrinin production in the filamentous fungus Monascus ruber. Appl Environ Microbiol 66(3):1120-1125.

93. Lee BK, Park NH, Piao HY, Chung WJ (2001) Production of red pigments by Monascus purpureus in submerged culture. Biotechn Bioprocess Eng 6(5): 341-346. 
94. Shepherd D, Carels M (1983) Product formation and differentiation in fungi. In: Smith JE (Eds.), Fungal Differentiation: A Contemporary Synthesis. Mycology 4 Marcell Dekker, USA.

95. Shin CS, Kim HJ, Kim MJ, Ju JY (1998) Morphological change and enhanced pigment production of Monasucs when cocultured with Saccharomyces cerevisiae or Aspergillus oryzae. Biotehnol Bioeng 59(5): 576-581.

96. Suh JH, Shin CS (2000a) Analysis of the morphologic changes of Monascus sp. J101 cells cocultured with Saccharomyces cereviasiae. FEMS Microbilogy Lett 193(1): 143-147.

97. Kim HJ, Kim JH, Oh HJ, Shin CS (2002) Morphology control of Monascus cells and scale-up of pigment fermentation. Process Biochemistry 38(5): 649-655.

98. Suh JH, Shin CS (2000b) Physiological analysis on novel coculture of Monascus sp. J101 with Saccharomyces cereviasiae. FEMS Microbiology Lett 190(2): 241-245.

99. Bau YS, Wong HC (1979) Zinc effects on growth, pigmentation and antibacterial of Monascus purpureus. Physiology Plant 46(1): 63-67.

100. McHan F, Johnson GT (1970) Zinc and amino acids: important components of a medium promoting growth of Monascus purpureus. Mycologia 62(5): 1018-1031.

101. Chiu SW, Poon YK (1993) Submerged production of Monascus pigments. Mycologia 85(2): 214-218.

102. Hajjaj H, Blanc PJ, Goma G, Francois J (1998) Sampling techniques and comparative extraction procedures for quantitative determination of intra- and extracellular metabolites in filamentous fungi. FEMS Microbiology Lett 164(1): 195-200.

103. Sekiguchi J, Gaucher GM (1977) Conidiogenesis and secondary metabolism in Penicillium urticae. Applied Environmental Microbiology 33(1): 147-158.

104. Calam CT (1976) Starting investigational and production cultures. Process Biochemistry 11: 7-12.

105. Smith GM, Calam CT (1980) Variations in inocula and their influence on the productivity of antibiotic fermentations. Biotechnology Letters 2(6): 261-266.

106. Calam CT, Smith GM (1981) Regulation of the biochemistry and morphology of Penicillium chrysogenum in relation to initial growth. FEMS Microbiology Letters 10(3): 231-234.

107. Palo MA, Vidal-Adeva L, Maceda LM (1960) A study on ang-kak and its production. Philippine Journal of Science 89: 1-19.

108. Sheu F, Wang CI, Shyu YT (2000) Fermentation of Monascus purpureus on bacterial cellulose-nata and the color stability of Monascus-nata complex. Journal of Food Science 65(2): 342-345.

109. Lim HS, Yoo SK, Shin CS, Hyun YM (2000) Monascus red pigment overproduction by coculture with recombinant Saccharomyces cerevisiae secreting glucoamylase. The Journal of Microbiology 38(1): 48-51.

110. Forage RG, Harisson DEF, Pitt DE (1985) Effect of environment on microbial activity. In: Bull A \& Dalton H (Eds.), Comprehensive Biotechnology. Pergamon Press, Oxford 220(2): 387-401.

111. Stanbury PF, Whitaker A (1984) Principles of Fermentation Technology. Pergamon Press, New York, USA.

112. Krairak S, Yamamura K, Nakajima M, Shimizu H, Shioya S (1999a) On-line monitoring of fungal cell concentration by dielectric spectroscopy. Journal of Biotechnology 69: 115-123.
113. Musaalbakri AM, Ariff A, Rosfarizan M, Ismail AKM (2006) Kinetics and modeling of red pigment fermentation by Monascus purpureus FTC 5391 in 2-litre stirred tank fermenter using glucose as a carbon source. Journal of Tropical Agriculture and Food Science 33(2): 277 284.

114. Mohamed MS, Mohamad R, Ramanan RN, Musaalbakri AM, Arif A (2009) Modelling of oxygen transfer correlations for stirred tank bioreactor agitated with atypical helical ribbon impeller. American Journal of Applied Science 6(5): 735-743.

115. Hamdi M, Blanc PJ, Gom, G (1996) Effect of aeration conditions on the production of red pigments by Monascus purpureus growth on prickly pear juice. Process Biochemistry 31(6): 543-547.

116. Malfait JL, Wilcox DJ, Mercer DG, Barker LD (1981) Cultivation of a filamentous mold in a glass pilot-scale airlift fermentor Biotechnology and Bioengineering 23(4): 863-877.

117. Yang J, Chen Q Wang W, Hu J, Hu C (2015) Effect of oxygen supply on Monascus pigments and citrine production in submerged fermentation. Journal of Bioscience and Bioengineering 119(5): 564-569.

118. Maniyom S, Markx GH (2012) Biomass and pigment production by Monascus during miniaturized submerged culture on adlay. World Academy of Science and Technology, International Journal of Chemical, Molecular, Nuclear, Materials and Metallurgical Engineering 6(8): 813-818.

119. Wong HC, Bau YS (1978) Morphology and photoresponses of fast-neutron and X-Ray-induced strains of Monascus purpureus. Mycologia 70(3): 645-659.

120. Mapari SA, Meyer AS, Thrane U (2006) Colorimetric characterization for comparative analysis of fungal pigments and natural food colorants. J Agric Food Chem 54(19): 7027-7035.

121. Kim CH, Kim SW, Hong SI (1999) An integrated fermentationseparation process for the production of red pigment by Serratia sp. KH-95. Process Biochemistry 35: 485-490.

122. Wu WT, Wang PM, Chang YY, Kuang TK, Chien YH (2000) Suspended rice particles for cultivation of Monascus purpureus in a tower-type bioreactor. Appl Microbiol Biotechnol 53(5): 542-544.

123. Vendruscolo F, Buhler RMM, de Carvalho JC, de Oliveira D, Moritz DE, et al. (2016) Monascus: a reality on the production and application of microbial pigments. Appl Biochem Biotechnol 178(2): 211-223.

124. Chen G, Shi K, Song D, Quan L, Wu Z (2015) The pigment charcteristics and productivity shifting in high cell density culture of Monascus anka density. BioMed Central Biotechnology 15(72): 1-9.

125. Srivastav P, Yadav VK, Govindasamy S, Chandrasekaran M (2015) Red pigment production by Monascus purpureus using sweet potato-based medium in submerged fermentation. Nutrafoods 14(3): 159-167.

126. Panesar R, Kaur S, Panesar PS (2015) Production of microbial pigments utilizing agro-industrial waste: a review. Current Opinion in Food Science 1: 70-76.

127. Musaalbakri AM, Samat N, Kasran M, Hassan H (2017) Proximate and amino acids composition of Monascus fermented products with potential as functional feed ingredients. Cogent Food and Agriculture 3(1): 1295767.

128. Chen W, Zhou Y, Shao Y, Feng Y, Li M, et al. (2015) Edible filamentous fungi from the species Monascus: Early traditional fermentations, moderns molecular biology, and future genomics. Comprehensive Reviews in Food Science and Food Safety 14(5): 555-567. 
129. Shao Y, Lei M, Mao Z, Zhou Y, Chen F (2014) Insights into Monascus biology at the genetic level. Appl Microbiol Biotechnol 98(9): 3913922. 